\title{
Experiencias comunitarias en defensa del agua en distritos rurales de Puntarenas, Costa Rica (2005-2017)
}

Recibido: 19 de junio 2017

Revisado: 1 de agosto 2017

Aprobado: 27 de septiembre 2017

Dany Villalobos

Villalobos

Costarricense. Geógrafo.

Estudiante de la

Licenciatura en Geografía en la Universidad de Costa Rica. Consultor ambiental e investigador independiente. Correo electrónico: danyvlobosucr@gmail.com

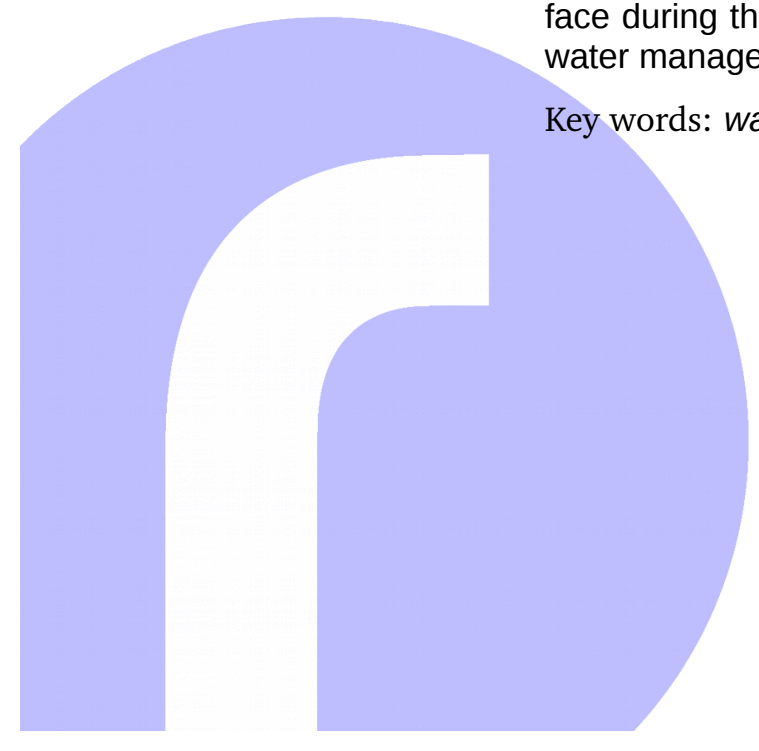

http://investiga.uned.ac.cr/rupturas/

Rev. Rupturas 8(1), Costa Rica, Ene-Jun 2018. ISSN 2215-2466. pp 131-166.
Resumen: La progresiva disminución hídrica en el cantón Central de Puntarenas se ha traducido durante los últimos años en conflictos. Ante este escenario, personas de diferentes pueblos se han organizado y coordinado acciones para cambiar el modelo actual de explotación y distribución injusta del agua. En este artículo se describen los conflictos a partir del trabajo realizado por el autor desde 2013 al presente con organizaciones de la zona. Dentro del repaso, se profundizará en el conflicto de Guacimal, que ha puesto en evidencia las dificultades que enfrentan los actores comunitarios para defender este bien público en el actual modelo de gestión institucional del agua.

Palabras clave: agua; conflictos; organización social; comunidades; Puntarenas

\section{Community-based water defends efforts within the rural districts in Puntarenas, Costa Rica (2005-2017)}

Abstract: The gradual decrease in the amount of water sources in the Central County of Puntarenas has given way to conflicts during the last few years. Therefore, people in the affected communities have become organized and have taken action to change the current unjust method of water distribution and usage. In this article, the work of the author inregards to this conflict within these community organizations which started in 2013 is described. The emphasis will be given on the conflict around the community of Guacimal. This particular conflict has evidenced all the various issues that communities face during their defense of this resource in the current government model of manement.

Key words: water; conflicts; social organization; communities; Puntarenas 


\section{Introducción}

Los territorios puntarenenses al norte del golfo de Nicoya han sido testigos de cambios notables en el ciclo del agua de sus cuencas durante el presente siglo. Hay una disminución progresiva de los caudales superficiales y subterráneos que es percibida por los habitantes de las comunidades locales. El fenómeno coincide con las proyecciones científicas desarrolladas para la región sobre cambio climático.

La percepción social de tener menor disponibilidad de agua lleva a problematizar los intereses existentes sobre el recurso hídrico, pasando después a la organización de acciones a escala colectiva. Las pretensiones de algunos actores locales sobre el agua se vuelven contrapuestas entre sí, al punto de producirse conflictos, de mayor o menor intensidad según sean las interpretaciones de la población local sobre tales intereses. Varias comunidades, desde la parte alta hasta las cercanías costeras, han reaccionado estos últimos años cuando sintieron amenazadas sus fuentes de agua o cuando observaron daños materializados que les significaron afectaciones directas.

La recopilación de las experiencias comunitarias ha tenido su base principal en el trabajo directo que ha mantenido el autor a partir del año 2013 con organizaciones comunales de la zona. Sin embargo, el repaso regional de los conflictos obliga a incluir otros casos suscitados previamente en las zonas rurales de Puntarenas mediante el apoyo de entrevistas e información disponible en medios.

Se profundizará particularmente en el conflicto de Guacimal que ha presentado gran complejidad y que en su desarrollo ha requerido constante debate con las instituciones responsables de la materia hídrica, usando los mecanismos de denuncia ambiental existentes, pero también acción directa en momentos clave.

Como conclusiones para el trabajo se analizan los desafíos de las organizaciones comunales y se explica a nivel general el potencial para resolver estas problemáticas locales en el marco de políticas y legislación de alcance nacional, según los aprendizajes obtenidos en las experiencias comunitarias.

El artículo pretende ser un aporte geográfico e histórico que sistematiza los sucesos que se desarrollan en pueblos de Puntarenas a inicios del siglo XXI, cuando se empiezan a ampliar discusiones locales sobre los problemas ambientales, analizando el papel del Estado y la sociedad en la resolución de esos problemas.

\section{Enfoque y acción social desde la geografía}

La geografía es una disciplina que tiene por objeto estudiar los fenómenos que transforman un territorio. Se asume la responsabilidad de escoger e interpretar los fenómenos que toman lugar y acción en un espacio geográfico 
delimitado. Como en toda ciencia, se parte de la existencia de uno o varios problemas que orientan el trabajo.

En Puntarenas se identificó el agua como un elemento clave para poder explorar las dinámicas actuales de conflicto social. Ha sido notable su capacidad para convocar a las poblaciones humanas a discutir el impacto de sus propias acciones en el territorio. La relación entre ser humano y agua ha empezado a colocarse en el centro de los intereses colectivos, que son los que mayor peso tienen en los ciclos de transformación territorial.

Con este trabajo se documenta la geografía del agua en Puntarenas vista como resultado de un proceso de investigación y acción participativa. Ha llevado implícita la tarea de interpretar las relaciones que se dan entre el espacio hidrológico y el humanizado, para lo que corresponde confrontarse con variables que pasan por la historia local, las subjetividades sociales propias de los contextos rurales, los elementos estrictamente técnicos y las contradicciones y los límites jurídicos en materia ambiental, entre otros.

Por tanto, este no es el resultado de un plan de investigación con delimitaciones predefinidas. Ha sido un reto profesional que permitió trascender las perspectivas reduccionistas para aprender en el camino. Después de cuatro años de trabajo con comunidades en conflictos sociales por agua en Puntarenas, el recorrido ha presentado diversos escenarios. Participar de lleno en esta experiencia ha requerido una dedicación en ocasiones intensiva y, en general, disponer de flexibilidad para responder a las circunstancias en tiempos colectivos, teniendo como meta la consecución de objetivos claros y consensuados.

La Investigación Acción Participativa (IAP) ha sido el enfoque que ha motivado este trabajo con comunidades puntarenenses. ${ }^{1}$ La IAP se caracteriza por utilizar metodologías flexibles, primando el diálogo constante con los diversos actores y su percepción de los problemas locales. Ha implicado un acercamiento estrecho con las realidades de la localidad como espacio colectivo, transformado por sentimientos y pensamientos humanos (Calderón y López, 1. La IAP tiene como fin el logro de la justicia social mediante el apoyo a las actividades impulsadas por personas con poco poder y medios que se organizan para 2013).

Uno de los esfuerzos iniciales para poder sostener este trabajo con comunidades alrededor del tema del agua fue el Plan de Vinculación Comunal, un proyecto estudiantil impulsado desde la Asociación de Estudiantes de Geografía de la Universidad de Costa Rica (UCR) en el 2014. Se comenzaron a hacer giras a la zona para poder así identificar problemáticas de agua en el contexto puntarenense. Luego de eso, otros programas institucionales de acción social como Kioscos Socioambientales para la Organización Comunitaria se han sumado a apoyar en el fortalecimiento de los procesos comunales. 
Imagen 1. Guacimal. Inducción a la comunidad con estudiantes de geografía en 2014.

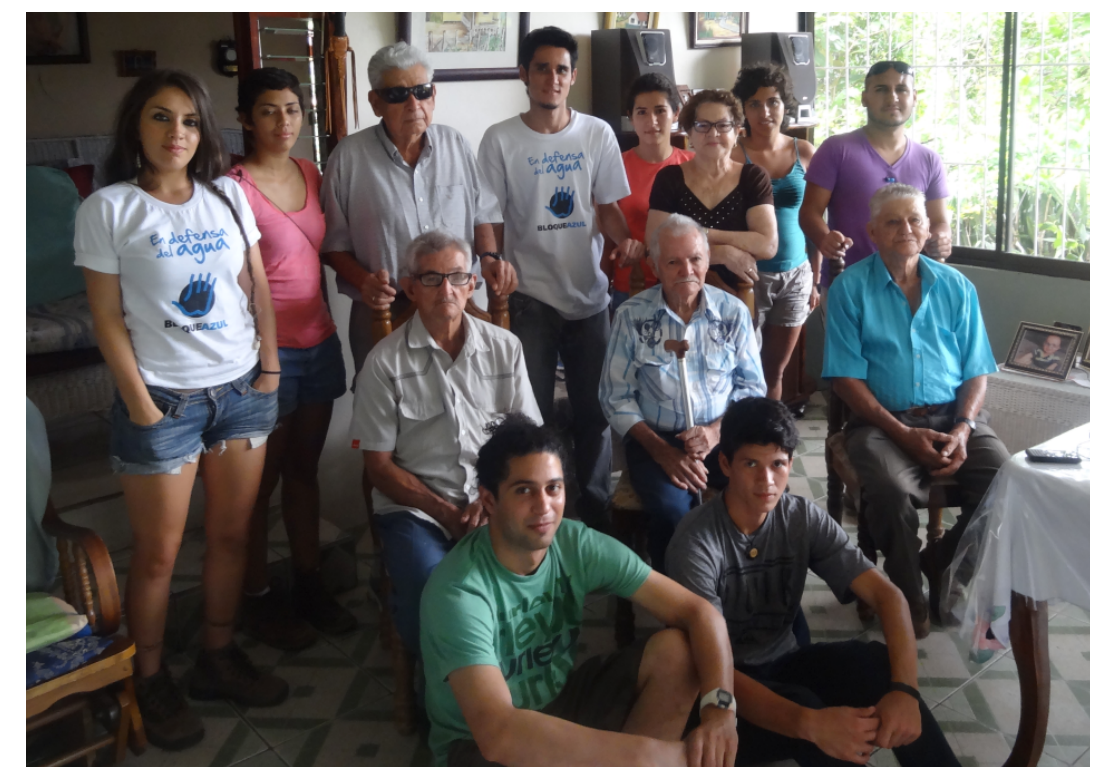

Fuente: Dany Villalobos s.f.

Los razonamientos de la gente local se inspiran en la experiencia vivida del

2 Concepto desarrollado por Orlando Fals Borda en su trabajo con comunidades colombianas. territorio que conocen y sienten suyo. Personas senti-pensantes ${ }^{2}$ han sido las detonantes de las acciones comunales para la defensa del agua en Puntarenas. Al final, no son solo las experiencias o percepciones individuales, sino las colectivas, las comunes, las que logran hacer que se trascienda el carácter de problemas personales/individuales o de índole privada a confrontaciones públicas que han sido objeto de estudio.

\section{La geografía del agua en Puntarenas}

El cantón Central de Puntarenas se puede dividir en tres grandes unidades territoriales: (1) el territorio peninsular, (2) el espacio marítimo del golfo de Nicoya con sus islas y (3) el territorio al norte del golfo de Nicoya. Es en este último sector donde se enmarcarán los casos documentados.

El territorio norte de Puntarenas se extiende desde el golfo de Nicoya hasta la divisoria continental de aguas en la cordillera de Tilarán. En la parte alta, las áreas protegidas propician el nacimiento de ríos como el Abangares, el Lagarto (límite Puntarenas-Guanacaste), el Guacimal y el Aranjuez (límite con el cantón Montes de Oro).

La cordillera de Tilarán es la autora natural este territorio. Está compuesta por antiguos volcanes extintos, que forman paisajes con densas serranías en donde los suelos se han desarrollado gracias a los ambientes montañosos que se establecieron sobre las antiguas coladas de lava, convertidas hoy en el piso rocoso de las cuencas medias y altas. 
Imagen 2. Ubicación del cantón central de Puntarenas.

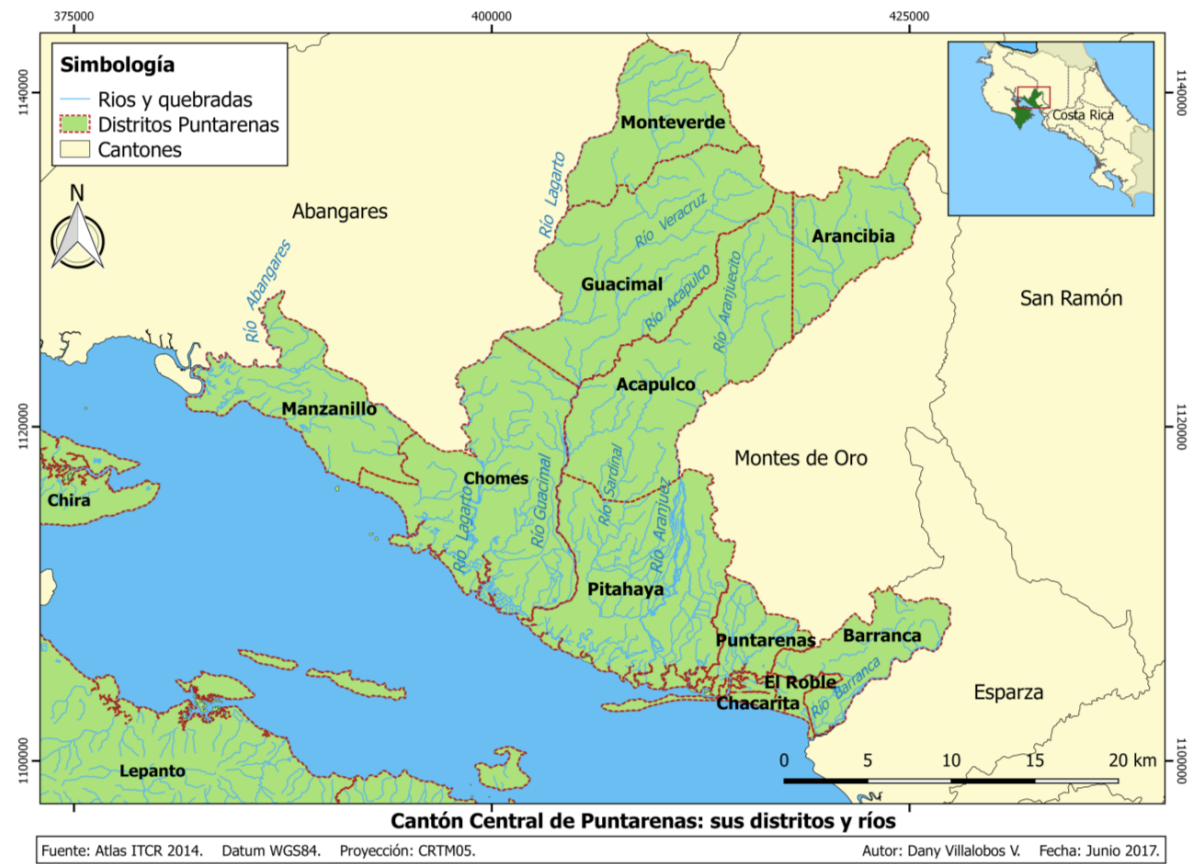

Fuente: Elaboración propia con QGis

Los ríos Lagarto, Guacimal, Aranjuez y sus afluentes han tomado curso por los fallamientos y valles rocosos entre los cerros, arrastrando por milenios los materiales cordilleranos que dieron origen a las extensas llanuras sedimentarias sobre las que se localizan hoy los distritos Pitahaya, Chomes y Manzanillo.

Imagen 3. Paisajes ganaderos dominantes en las serranías, sector Veracruz (izq.) y en las llanuras sector Sardinal (der). Agosto del 2014.

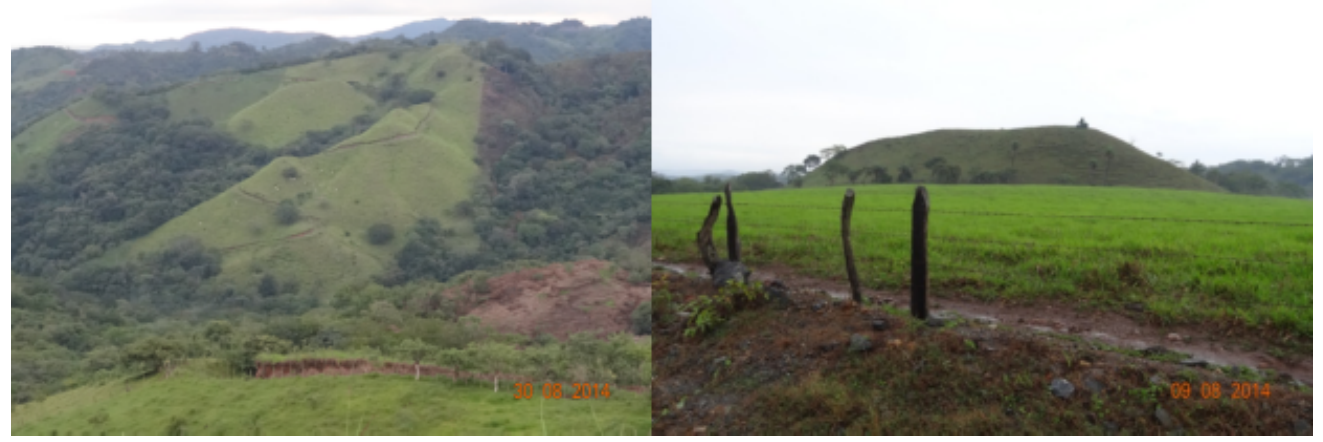

Fotos: Dany Villalobos. 
Desde la segunda mitad del siglo XX, se estableció la ganadería extensiva en la zona, se deforestaron amplias zonas de bosques, impidiendo así el ciclo de desarrollo de nuevos suelos y compactando los existentes por el tránsito masivo de los animales. Se puede interpretar el impacto de estas alteraciones como causante de erosión, especialmente en las laderas y la configuración de un ambiente que limita la infiltración y el consecuente almacenamiento del agua en los subsuelos, viéndose afectadas las reservas hídricas subterráneas y, de esta forma, las fuentes de agua conocidas.

En las zonas bajas se ha combinado la ganadería extensiva con otras actividades agroindustriales. Principalmente, hay cañales dominando las haciendas. También existen pastos para cosecha de pacas de forraje que se comercializa, principalmente, en la estación seca. La industria cañera ha tomado el frente de expansión de la frontera agrícola en el manglar, depredándolo progresivamente. Además, ha habido expansión piñera establecida en Hacienda Chapernal, Piatahaya. En Chomes se han cultivado amplias áreas de algodón y más recientemente de palma aceitera. Dichas actividades realizan un alto consumo de agua y algunas como el algodón y la piña hacen uso intensivo de agroquímicos que afecta además su calidad y a los ecosistemas.

\section{Imagen 4. Paisajes de agroindustria piñera en Chapernal, 2014 (izq.) y terreno cosechado de industria algodonera en Chomes, 2017 (der.).}

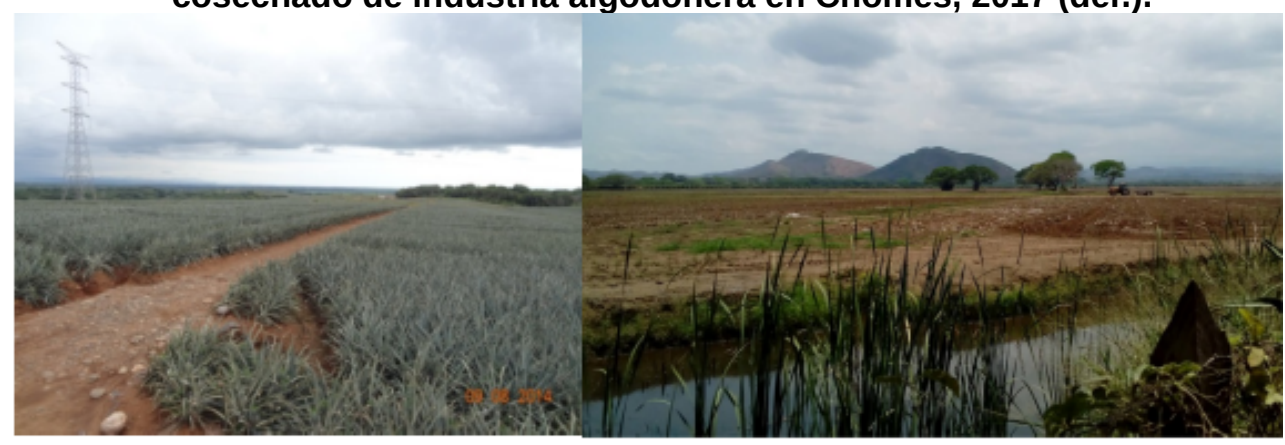

Fotos: Dany Villalobos.

3. Unidad administrativa utilizada por la Dirección de Aguas de MINAE según la división nacional en 34 cuencas. Dentro de ella se ubican los ríos citados en este artículo.
En la cuenca de Abangares ${ }^{3}$ hay una disminución progresiva de los cuerpos de agua superficiales y subterráneos, la cual es percibida por los habitantes. Se comprueba entonces la influencia del cambio climático global, que proyecta tener escenarios de menor precipitación y mayores temperaturas para la zona (Cifuentes, 2010), lo que progresivamente iría afectando las reservas hídricas. Según el MINAE (2008), Abangares es la cuenca de menor recarga media anual con el agravante de registrar una de las mayores tasas de extracción para fines agrícolas, domésticos y turísticos. El territorio puntarenense se caracteriza por tener una estación seca bien marcada, en promedio de 6 meses. Como promedio histórico del periodo 1970-2005 precipitaron entre $2611 \mathrm{~mm}$ anuales en Monteverde (zona alta) y $1672 \mathrm{~mm}$ en Puntarenas (Araya y Sanabria 2010). Pero el año hidrológico varía anualmente de acuerdo 
con la influencia de fenómenos climáticos como La Niña y El Niño. Este último fue responsable de la extensión extraordinaria de los periodos secos, cada vez más intensos en las últimas décadas.

En este contexto, los ríos, cada vez menos caudalosos en la época seca, se ven aún más agredidos por las captaciones masivas de agua para técnicas de riego por aspersión para agroindustria y ganadería. También por las extensas redes de canales que desvían el agua para los cañales en las áreas de cultivo durante los meses secos.

Otros factores humanos, que intervienen y transforman los ríos son los quebradores o las concesiones de cauce de dominio público (CDP). Desde el río Barranca al Este, hasta el Abangares al oeste, los cauces están dominados por concesiones mineras en su parte baja, activas o en proceso de aprobación, generando conflictividad, aunque no ha habido procesos de organización comunal sostenidos en el tiempo para confrontarlos.

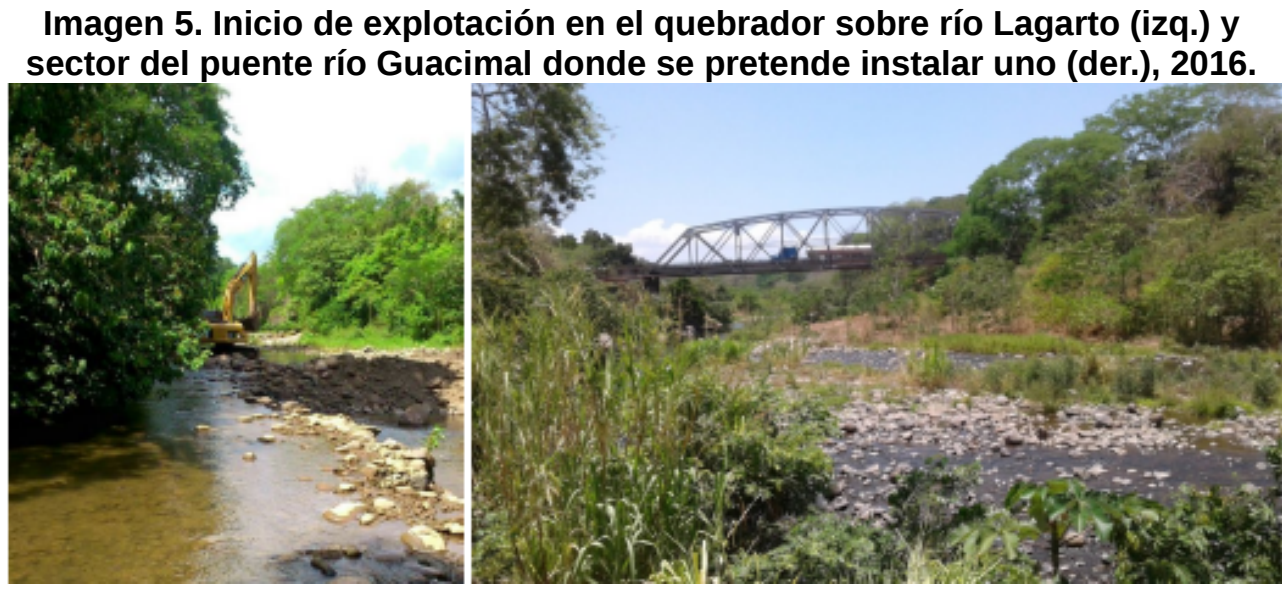

Fotos: Dany Villalobos

Todas estas alteraciones, desencadenan una serie de efectos. Por ejemplo, si un río con un caudal aproximado de 1000 litros por segundo (L/s) como el Guacimal $^{4}$ deja de llegar al mar en estación seca como naturalmente lo hacía, los ecosistemas adyacentes estarán dejando de percibir un volumen de 86400 metros cúbicos de agua diarios, teniendo por lógica una serie de im-

4. Caudal medido el 25 de mayo de 2009 según el Registro Nacional de Concesiones del MINAE pactos. Y si por cada hectárea de cultivo la agroindustria utiliza varios kilogramos anuales de químicos sintéticos de alto tiempo de residencia ambiental, las miles de hectáreas cultivadas en total estarán manteniendo procesos sostenidos de contaminación que alterarán procesos biológicos en los suelos y los humedales. 
5. Datos referidos en conversaciones con personas de Guacimal que frecuentan la zona.

\section{Protestas colectivas por agua (2005-2017)}

En el inicio del presente siglo, el reconocimiento del cambio climático a escala global produjo un aumento en la información mediática e institucional sobre este fenómeno. Mientras esta campaña avanzaba, posicionando el campo ambiental como un aspecto vulnerable, también se empezaron a percibir en el territorio puntarenense cambios más marcados en los cuerpos de aguas como ríos, quebradas y nacientes que han ido disminuyendo o secándose según su ubicación y el comportamiento del tiempo atmosférico anual. Ante los vacíos prácticos en materia de sostenibilidad ambiental y deficiencias en la gestión hídrica del Estado, la gente comenzó a posicionar sus criterios ante proyectos y necesidades en diferentes lugares de Puntarenas.

\section{Defensa de las quebradas de Monteverde (2005)}

Fue en Monteverde donde sucedió uno de los primeros conflictos por agua que adquieren carácter colectivo en la zona. En enero del 2005, vecinos de la comunidad se interpusieron contra la maquinaria que construía una tubería de $6 \mathrm{~km}$ de extensión que extraería aguas de las quebradas Máquina y Cuecha para beneficio de la empresa Rogumeca S.A. y la Sociedad de Usuarios de Agua Guzmith, formada por empresarios de Santa Elena. Este grupo de vecinos denunciaba que los permisos fueron dados con carencia de un Estudio de Impacto Ambiental a pesar de que las dos quebradas eran hábitat de especies que catalogadas en peligro de extinción (Gamboa 2005).

Los empresarios terminaron por construir su proyecto, pues se deshicieron de la oposición comunal demandando a 17 personas que participaron de la acción colectiva, logrando interponerles medida cautelar de no acercarse a las construcciones. El sistema de riego terminaría explotando los 12,65 litros por segundo de agua que fueron concesionados por la Dirección de Aguas en el 2004 (Bolaños, 2005).

Según algunos testigos, el proyecto se encuentra aún en uso y es aprovechado por empresas locales como la fábrica de quesos Monteverde, la estación de combustibles y algunos restaurantes que mantienen jardines verdes. ${ }^{5}$

\section{Lucha por acceso a agua potable Villa Bruselas}

El pozo que abastecía a esta comunidad ubicada a orillas de la carretera interamericana, empezó a tender a la baja. Ello obligó a hacer racionamientos constantes y fuertes de agua, que llegaron a extenderse hasta por cinco días seguidos, según indicaron personas locales que fueron entrevistadas en 2016 por estudiantes del Trabajo Comunal del Programa Kioscos Socio-ambientales de la Universidad de Costa Rica.

Entonces tuvieron que reaccionar por la falta de respuesta satisfactoria por parte de Acueductos y Alcantarillados (AyA), responsable del servicio obtenido de un pozo cercano de Aranjuez. La promesa de trasladar la fuente a otro sitio tardó en llegar y cada verano se repetía la desesperante situación. Por esa razón realizaron bloqueos recurrentes. El 24 de marzo del 2014 por la 
mañana se registró el último bloqueo total de la carretera interamericana, sostenido hasta negociar una solución con las autoridades de AyA (Garita y Solano 2014). Con posterioridad se dio la reconexión del servicio gracias a la captación de nacientes en la zona de Zagala y Caballo Blanco.

Imagen 7. Panorámica de la entrada de Villa Bruselas, 2017.

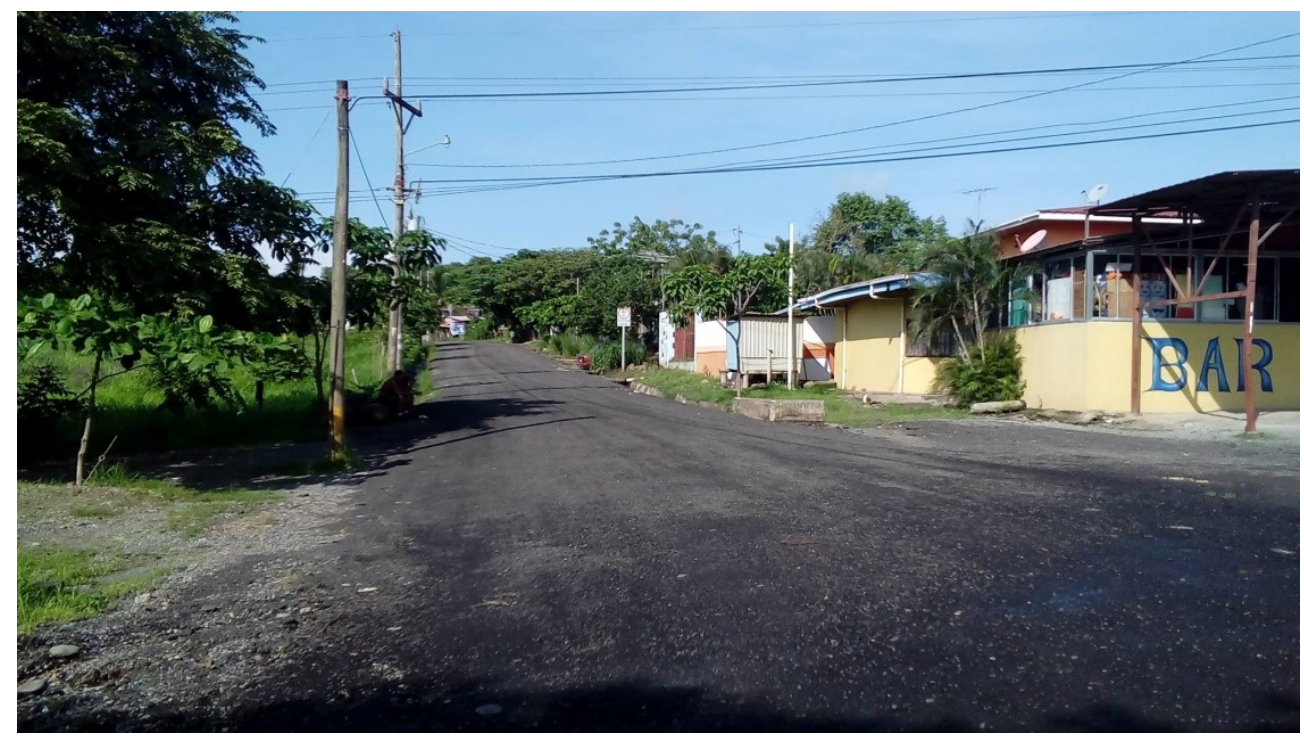

Foto: Dany Villalobos.

\section{Construcción del proyecto de riego sobre el río Aranjuecito}

En diciembre del 2014 se recibe aviso de una amenaza sobre un río pequeño de la zona: el Aranjuecito. En una gira realizada a la comunidad de ese mismo nombre y en ese mismo mes, se reunieron en la escuela local varias personas del pequeño poblado para explicar la situación vivida y solicitar colaboración en la defensa del río al grupo de estudiantes la Universidad de Costa Rica que participaban en el Plan de Vinculación Comunal.

Lo expresado ese día fue que les tomó por sorpresa ver la maquinaria excavando y enterrando tuberías de gran dimensión. Algunas personas de Aranjuecito sí habían escuchado rumores de la intención de un proyecto de riego sobre el río, pero aparte de eso no hubo información alguna para valorarlo en su comunidad. Fueron personas de San Rafael y Sardinal las que se reunían con el Servicio Nacional de Aguas Subterráneas, Riego y Avenamiento (SENARA) para acordar sus planes y conformar la Sociedad de Usuarios de Agua de Aranjuecito, que se beneficiaría de la explotación del río. 
6. Expediente 1087-2010SETENA
Imagen 8. Construcción en diciembre del 2014 y sitio de captación captando hasta el 90\% del agua en mayo de 2015.

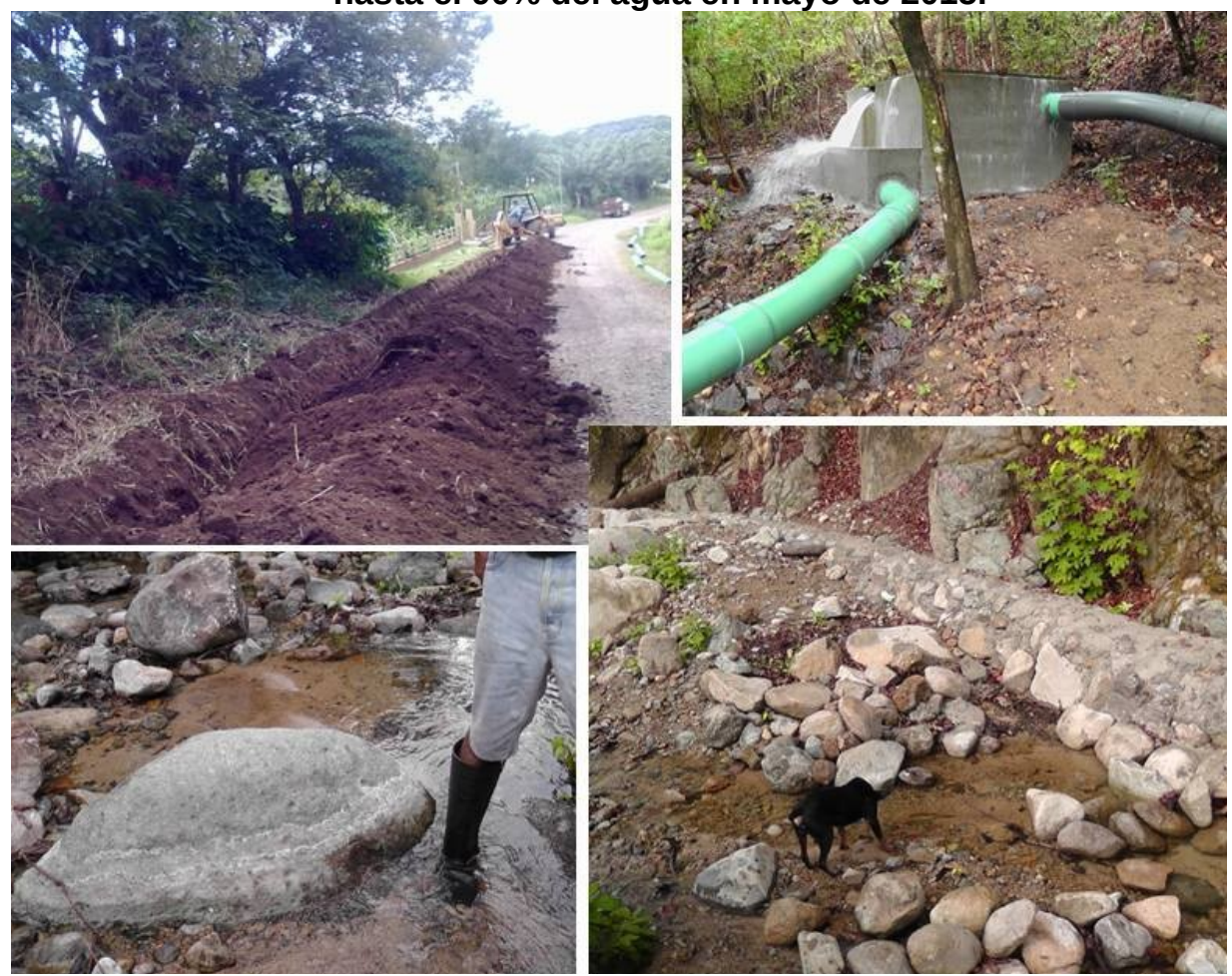

Fotos: Dany Villalobos.

La preocupación aumentó cuando Ronald Varela, presidente de la ASADA local, obtuvo por medios propios el expediente de SETENA, ${ }^{6}$ donde constataba que se había dado viabilidad ambiental sin estudios ambientales ni mayores cuestionamientos a una concesión de 61,54 litros por segundo de agua, a pesar de que se había llegado a medir, entre otros datos, 67,43 litros por segundo en el río en abril del 2008, lo que apuntaría un panorama devastador para el caudal, dejándolo prácticamente seco.La situación motivó a los estudiantes a comprometerse en la redacción de un recurso de amparo para plantearle a la Sala IV, con los argumentos dados por las personas en esa reunión, la necesidad de anular la viabilidad ambiental dada en la resolución N. ${ }^{\circ}$ 13832011-SETENA y consecuente concesión de aguas del río Aranjuecito, por perjudicar el derecho al ambiente sano y ecológicamente equilibrado de las personas de esa comunidad y habérseles excluido de información, lo que también violaba sus derechos.

Sin embargo, este caso no corrió con suerte. La Dirección de Aguas emitió su informe a la Sala IV y justificó que, según sus políticas y metodologías de cálculo, se permitía dejar como remanente el $10 \%$ de caudal medio anual y en casos extremos hasta un 5\%. Al enfocar un dato de $140 \mathrm{~L} / \mathrm{s}$ en abril del 2014 (tomado en otro sitio ubicado más de $2 \mathrm{~km}$ aguas debajo de la toma real) ar- 
gumentaron que quedaba más del $50 \%$ del agua en el río, de forma que se solicitaba rechazar el recurso. ${ }^{7}$ El análisis de datos era superficial y poco explicativo de la realidad ambiental de un río disminuido, pero la Sala orientaría su postura final por estas explicaciones. No hubo medida cautelar y la Sala IV rechazó el recurso interpuesto, argumentando que la Dirección de Aguas era 7. Documento DA-0164-2015 de la Dirección de Aguas en respuesta a la Sala IV en el el órgano técnico especializado en el ámbito y, según su criterio, no había irregularidad en la obtención de la concesión y, por tanto, no se lesionaban los derechos reclamados. ${ }^{8}$ El pueblo recibió la noticia con desesperanza en 8. Resolución № 2015005621 el sistema judicial del país. Posteriormente se sumarían a participar de los de la Sala Constitucional. procesos de lucha de otras comunidades que tenían problemas similares con sistemas de riego en la zona.Ese año 2015, con el apoyo de Thomas Shahady, profesor en ciencias ambientales de la Universidad de Lynchburg, Virginia (EE.UU.), y vecinos de la comunidad, se realizaron aforos $50 \mathrm{~m}$ por sobre el sitio de toma, que es de difícil acceso. Se llegaron a medir mínimos de 37,72 y $45,01 \mathrm{~L} / \mathrm{s}$ en junio y julio, respectivamente, en una extraordinariamente prolongada estación seca ese año por el fenómeno del Niño. Para entonces el proyecto estaba en periodo de pruebas técnicas y según estos registros, durante ese periodo, al abrirse por completo la llave de captación, el caudal pudo haber sido entubado en su totalidad. ${ }^{9}$

9. La concesión era de 54.33 L/s y para este año el río

Un efecto positivo del recurso de amparo fue que los desarrolladores tomaron la decisión de no construir el 100\% de los sistemas de riego -hasta ahora-, utilizando solamente las previstas para abrevadero que son de bajo consumo para evitar secar el río, lo que consideran les podría traer un problema legal que no quieren, según afirmó Eliecer Zumbado, presidente actual de la sociedad de usuarios. Él mismo afirmó en una conversación personal que solo cinco fincas beneficiarias disponen de riego actualmente.

\section{Desabastecimientos de agua potable en Sardinal}

Según el entonces presidente de la ASADA de Sardinal, José Arroyo, en el 2014 comenzaron a haber racionamientos de agua en este pueblo semiurbano. En Sardinal habitan unas 1500 personas según las estimaciones hechas a partir del número de usuarios de dicho acueducto.

El sistema de racionamientos se realizaba por sectores. En los periodos críticos se cortaba por horas en ciertos barrios, que por su ubicación requerían un periodo de almacenamiento previo para poder disponerla después. También se recurrió a cisternas a partir del 2015 por la criticidad de la condición de la naciente de la que se toma el agua.

Si bien esta comunidad pudo resolver los problemas sin tener que tomar acciones extra-administrativas, la situación permitió hacer conciencia sobre las contradicciones en las formas de acceso a fuentes de agua de la zona, pues mientras se realizaban cortes para el consumo humano y usos domésticos por la sequía, los finqueros de los alrededores regaban sus pastos con proyectos del SENARA como el de Aranjuecito, al igual que en las fincas piñeras justo al frente del poblado en Hacienda Chapernal. 


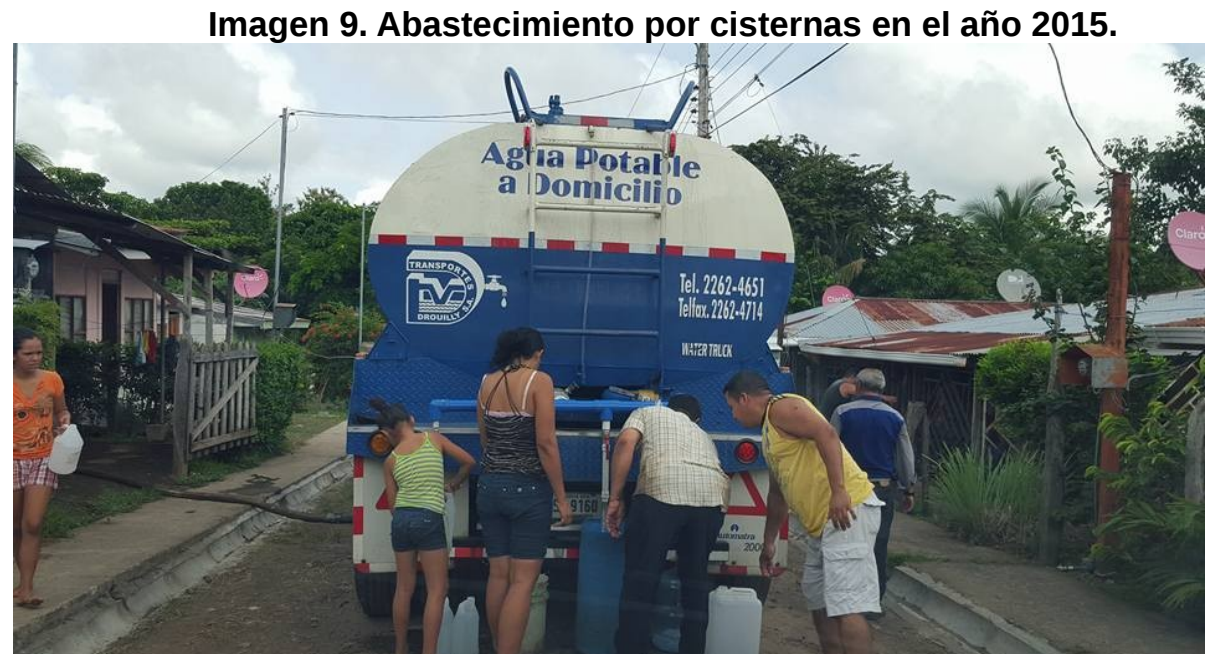

Foto: ASADA Sardinal

\section{Río Acapulco seco en Santa Rosa}

En el año 2002 se había construido un proyecto de riego en el poblado de Santa Rosa. Este se promovió para beneficiar ganaderos y agricultores en esa misma localidad, representados por la Sociedad de Usuarios de Agua de Santa Rosa, la cual obtuvo aquel año una concesión de $16 \mathrm{~L} / \mathrm{s}$ del río Acapulco, que se caracteriza por tener un muy bajo caudal en época seca. Sin embargo, a pesar de la toma, Acapulco mantuvo un flujo mínimo de agua con el que logró evadir la polémica durante los primeros 10 años de uso de la concesión.

Fue en el año 2015 que sucedió el colapso total del río. Tras renovar la concesión, ahora con 14,99 L/s, el déficit hídrico en la subcuenca llegó a un punto crítico y Carlos Fernández, abogado y propietario en la zona encontró el río notoriamente seco en marzo, según comentó. Inmediatamente dirigió una denuncia a la Dirección de Aguas.

10. Causa 15-000061-0989-PE

El 10 de abril de 2015 pudo ser documentada la sequía total del Acapulco, del Organismo de Investigación Judicial. Citado en Informe AT2285-2015 de la Dirección de Aguas.

esta vez mediante video (Era Verde 2015). La denuncia inicial se dirigió al Organismo de Investigación Judicial (OIJ) de Monteverde ${ }^{10}$ que la recondujo a la Dirección de Aguas. Por ambas denuncias se realizaron inspecciones el 24 de abril y 21 de mayo de ese año, encontrando flujo de agua en el río. Se

11. Informe AT-2285-2015 de la Dirección de Aguas. midieron 15,21 y $13,62 \mathrm{~L} / \mathrm{s}$, respectivamente, como caudal natural aguas arriba del sitio de toma y como remanente entre 7 y $5 \mathrm{~L} / \mathrm{s}$ aguas abajo del sitio de captación. ${ }^{11}$ 
Imagen 10. Río seco a la altura del puente de Acapulco, camino a Monteverde en junio del 2015.

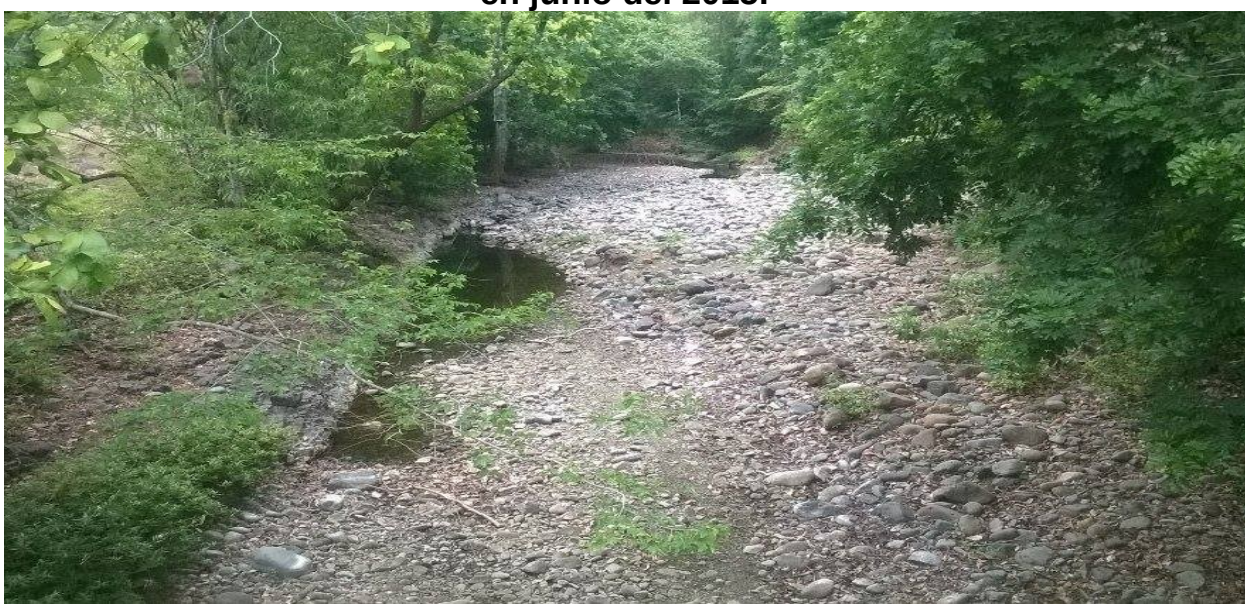

Fotos: Dany Villalobos.

Aunque con este registro quedó en evidencia que el río había llegado a tener un caudal menor de los 14,99 L/s concesionados, no hubo mención ni acciones correctivas por parte de la Dirección de Aguas, órgano responsable de otorgar y fiscalizar las concesiones. No se asociaron los datos para confirmar que la denuncia por sequía hecha por los testigos oculares guardaría relación con el uso de la concesión del proyecto de riego, lo que indignó a los vecinos que esperaban ver una intervención oficial en este problema y sanciones para los responsables.

Por esa razón, decidieron emprender acciones junto con las organizaciones de Guacimal, que desde hacía dos años venían expresando su oposición contra otra concesión cercana -que no se había ejecutado aún- en el río Veracruz, por ser considerada excesiva.

\section{La formación de la Alianza de Comunidades por la Defensa del Agua}

Un problema común se empezaba a visibilizar en tres lugares diferentes: Guacimal, Santa Rosa y Aranjuecito. Se trataba de los proyectos de riego impulsados por el SENARA y sus permisos obtenidos en el MINAE sin estudios que garantizaran la estabilidad ambiental de los caudales.

El colapso total del río Acapulco en Santa Rosa demostró lo que denunciaron casi paralelamente los líderes comunales de Guacimal y Aranjuecito: la posibilidad de que, por las captaciones pretendidas para sistemas de riego, sus ríos fueran secados total o parcialmente dependiendo de la variabilidad climática durante el año.

Este problema llevó a un acercamiento entre personas de las comunidades mencionadas. La decisión fue unirse para denunciar la amenaza de los proyectos de riego y apoyar otros casos de comunidades que luchaban por de- 
fender sus aguas. Así, se formó la Alianza de Comunidades por la Defensa del Agua en el cantón Central de Puntarenas, el domingo 11 de mayo del 2015.

Imagen 11. Reunión-taller donde comités locales crean la Alianza por la Defensa del Agua. Casona de Guacimal, 11 de mayo del 2015.

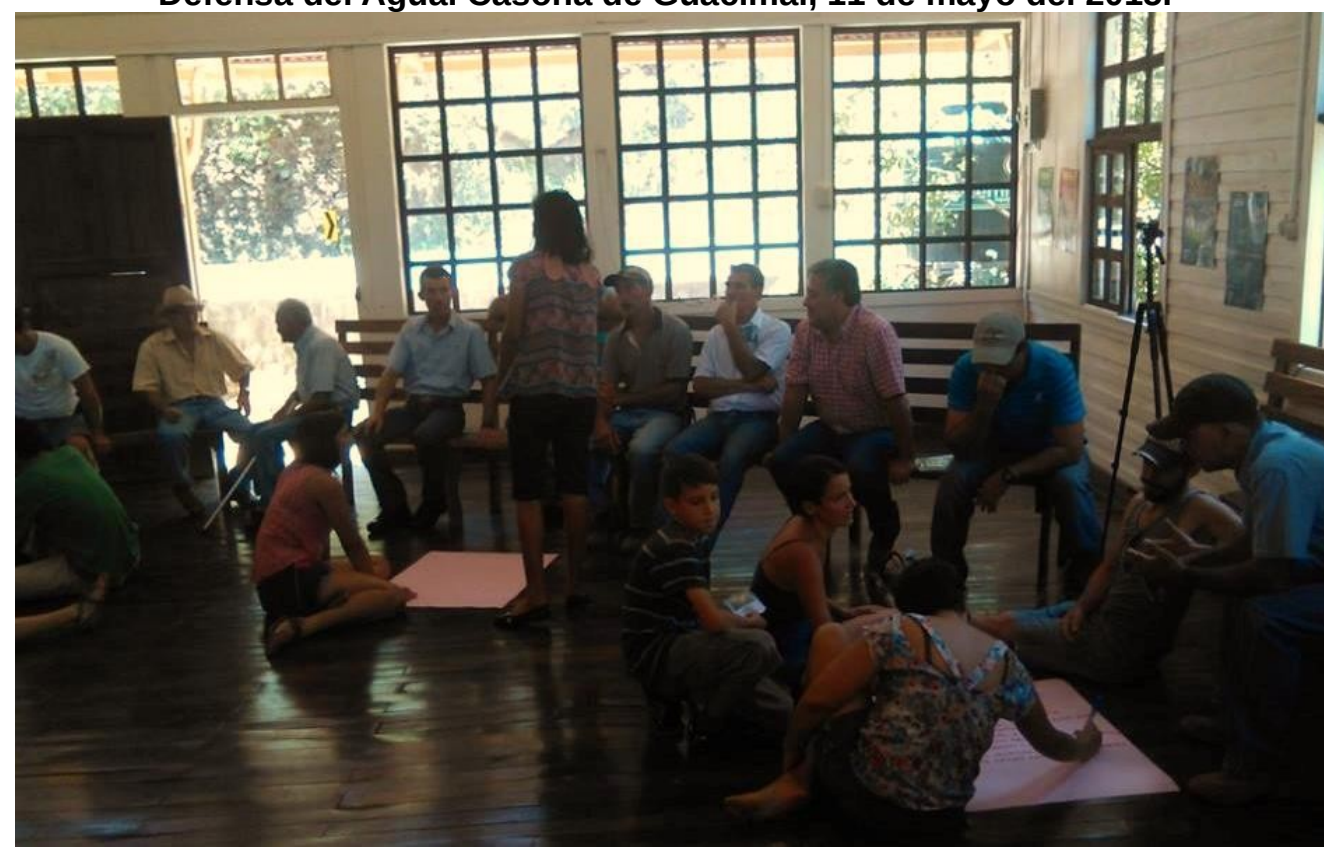

Foto: Manuel Zúñiga

La dinámica acordada fue mantener reuniones cada 22 días para discutir y concretar acciones contra las irregularidades que amparaban los proyectos de riego y acuerpar a otras comunidades en donde aparecieran nuevas amenazas a las fuentes de agua. Así se mantuvo por varios meses hasta que las condiciones fueron cambiando en Guacimal, lo que llevó a trascender la dinámica de las reuniones y elaboración de documentos para pasar a acciones de calle, que fueron acompañadas por estas comunidades integrantes.

\section{El colapso del acueducto de La Pita de Chomes}

El día que se formó la Alianza se presentaron a la reunión personas de la ASADA de La Pita de Chomes, un poblado cercano a la carretera interamericana en el sector de Lagarto. Este acueducto tenía un convenio con la ASADA de Guacimal por los problemas de calidad de agua que había venido presentando con su pozo, en donde se identificaron altas concentraciones de hierro y manganeso que afectaban no solo la potabilidad sino también llegaban a manchar la ropa al lavarse, según los testimonios. 
Según constaba en documentos de la ASADA, se había acordado desde el año 2009 que se iba a captar una naciente en una finca privada de Guacimal. Sin embargo, llegó el 2015 y con el fenómeno de El Niño, el 9 de julio sucedió el colapso total del pozo, según narró Marvin Jiménez, quien era presidente de la ASADA.

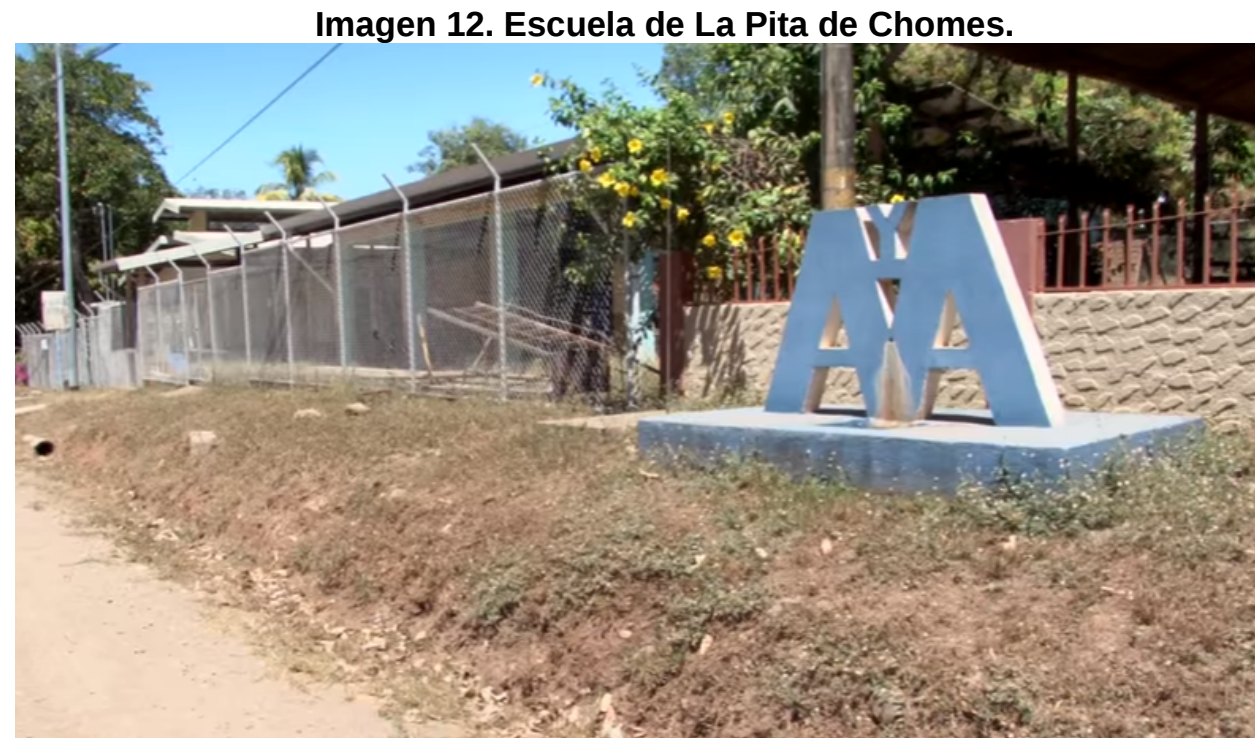

Foto: Era Verde UCR.

La comunidad se quedaba sin acceso a agua potable y algunos incumplimientos que se achacaban al AyA y la ASADA de Guacimal habían impedido completar la ejecución del compromiso, por lo que se urgía una solución de emergencia que sería conectar el último tramo de la ASADA de Guacimal al tanque de La Pita que estaban separados por menos de un kilómetro, con el fin de llenarlo por las noches y poder así distribuir al día siguiente, al menos, una dosis suficiente para solventar las necesidades más básicas.

La ASADA de La Pita tuvo que comprar agua por sus propios medios de un pozo artesanal de un finquero. Él mismo la repartía con un contenedor que transportaba con su chapulín. Sin embargo, no era agua potable y el AyA ni siquiera había gestionado el envío de cisternas a esta comunidad que insistía en una solución urgente.

Ante esta situación, los administradores del acueducto de La Pita percibían un ausentismo marcado de parte de la unidad de acueductos comunales de la regional de AyA EI Roble. Por este motivo se acordó en la segunda reunión de la Alianza, realizada en el salón comunal de Aranjuecito, para redactar un recurso de amparo para obligar al AyA a una solución definitiva, pues año tras año se habían repetido las excusas que postergaron las acciones necesarias para conectar la naciente destinada a La Pita. 
12. Resolución 2015019624 de la Sala Constitucional
Se abrió este proceso denunciando la violación al derecho al acceso al agua para unas 40 familias de la comunidad de La Pita y cómo esto afectaba de manera especial a niños que veían interrumpido su derecho a la educación por el cierre diario de la escuela. Además, muchos habitantes eran personas mayores de edad, lo que significaba un riesgo mayor para la salud por falta de agua, algo que se destacó en la denuncia ante la Sala IV (Cascante 2015), que al final sentenció al AyA y la ASADA de Guacimal a dar una solución sostenible en un plazo de 3 meses. ${ }^{12}$ Vale destacar que para el momento en que se resolvió esta problemática en diciembre de 2015, ya se había realizado la conexión provisional para restablecer el servicio de agua por parte de la ASADA de Guacimal.

\section{Ríos Aranjuez, Lagarto, Guacimal y Abangares secos por agroindustria}

La difusión mediática de casos como el de la sequía del Acapulco y la lucha por el río Veracruz, que se daba paralelo (para el cual dedicaremos el próximo segmento completo), inspiró la denuncia ambiental en la zona. Varias problemáticas con ríos que venían acentuándose o presentándose ya en años anteriores, empezaron a exponerse gracias a las redes sociales, utilizando la plataforma de la Alianza por la Defensa del Agua que se había posicionado ya en la opinión pública como una red que permitiría hacer presión pública y denuncia formal ante las autoridades para las situaciones que lo ameritaran.

\section{Río Aranjuez}

El 9 de mayo del 2015, en una gira de reconocimiento del Trabajo Comunal del programa Kioscos Socio-ambientales para la Organización Comunitaria de la Universidad de Costa Rica, se observó el cauce del río Aranjuez seco. Al mismo tiempo se podía notar cómo existían canales en la hacienda cañera adyacente al río, que conducían importantes flujos de agua, lo que sería resultado de desvíos aguas arriba, como se valoró con el docente Mauricio Álvarez.

Los cañales se caracterizan por tener densos sistemas de drenaje y aunque no se ha realizado un trabajo de seguimiento sistemático, se podría asumir que la alteración abrupta del caudal del río Aranjuez es un fenómeno que estaría sucediendo todos los años. Esta alteración supone una barrera a los procesos ecológicos del río, especialmente a las especies que se caracterizan por tener hábitos migratorios.

\section{Río Lagarto}

13. Registrado así en el Acta de observación policial del 29 de marzo del 2016.,

Delegación Policial Abangares, Ministerio de Seguridad Pública.'.
La mañana del 8 de abril de 2016, vecinos de comunidades que dependen de pozos en la parte baja del río Lagarto se organizaron para eliminar una presa ilegal que desviaba las aguas por un canal, dejando en el río aproximadamente un $30 \%$ de su caudal. ${ }^{13}$ Si bien no se pudo identificar el uso que se le daba a la captación ilegal, la acción llamó la atención sobre la importancia 
de defender los ríos por su papel fundamental en el abastecimiento de agua a poblaciones de Chomes y Abangares.

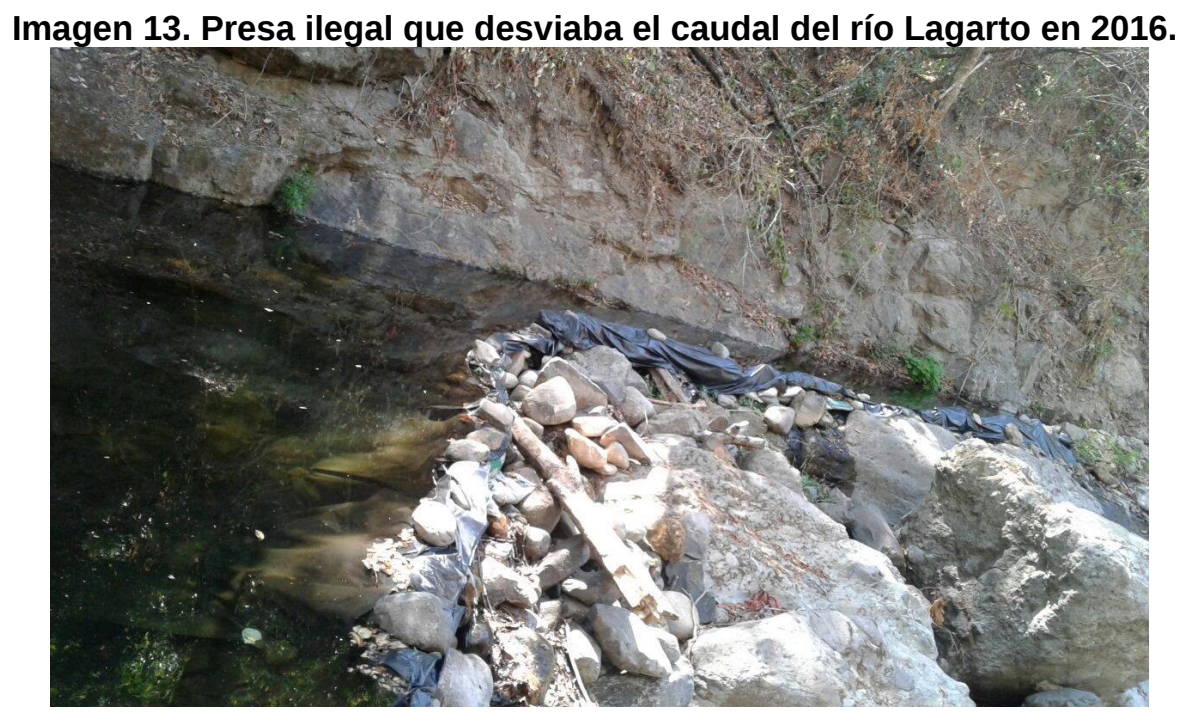

Foto: Marta Corrales

Varias ASADAS tienen pozos cerca del río, como Lourdes de Abangares, Malinche, Orocú, Cocorocas, Costa de Pájaros y Morales de Chomes. En la cercanía al mar era donde se evidenciaba con más claridad el desastre ambiental: donde antes pasaba el río Lagarto solo quedaban piedras y polvaredas en el camino que comunica Punta Morales con Chomes.

La Alianza promovió la redacción de una denuncia penal contra el propietario de la finca donde se ubicó este problema, con asesoría de estudiantes de Derecho de la Universidad de Costa Rica. Sin embargo, al final, el balance de presentar o no la demanda quedó en manos de las ASADAS y no se emprendió la acción, pero se acordó seguir actuando organizados, desmantelando presas ilegales y presentando denuncias en caso de reincidencia.

Otras presas, aguas más abajo, fueron también desmanteladas por vecinos de Orocú y Morales, ya que estaban terminando de consumir el caudal remanente y provocando la severa sequía del río a poco más de un kilómetro de llegar al golfo de Nicoya.

\section{Río Guacimal}

Derivado de las denuncias públicas sobre la destrucción del río Lagarto, hubo reportes en mayo del 2016 de que se secó también el río Guacimal. Aparentemente, no era la primera ocasión en que quedaba en ese estado. En una gira realizada a la zona, Edwin Aguirre, fontanero de la ASADA de Judas de Chomes y residente toda su vida en la zona explicó que la sequía ha sido tan 
sistemática que incluso podría haber causado el colapso de las poblaciones de un artrópodo de río que era conocido como "burra", muy similar a los camarones, que no ha vuelto a verse en este sector.

Los denunciantes facilitaron fotografías en donde se observaba el cauce del río Guacimal sin agua a la altura de Hacienda San Agustín de Chomes. Asociaban el colapso con los sistemas de riego por aspersión de la empresa piñera Banacol. Más adelante se explicarán los resultados de una revisión acerca de las concesiones otorgadas del río Guacimal en donde se confirmaría la hipótesis planteada por los vecinos sobre la piñera como agente de la sequía. Ellos solicitaron anonimato al hacerse pública la información.

\section{Imagen 14. Sequía del río Guacimal en Hacienda San Agustín (izq) y desvíos que afectaban al río Abangares en el sector de La Irma (der).}
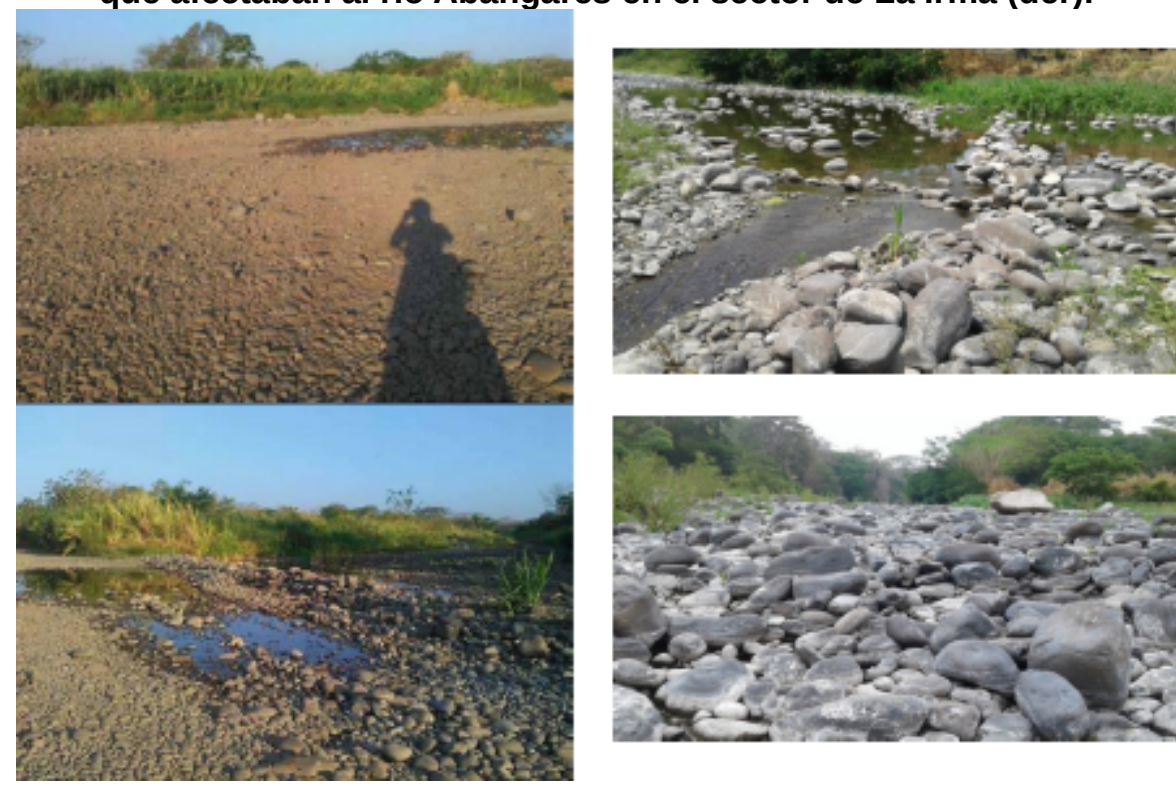

Fotos: Alianza Defensa del Agua.

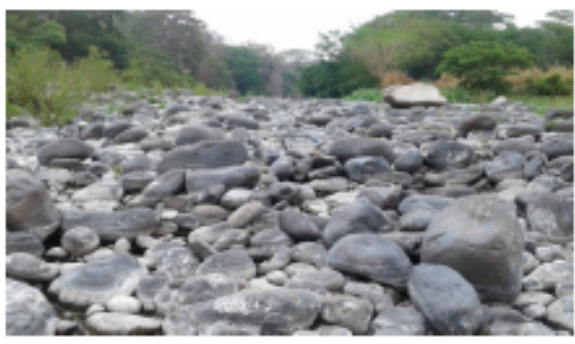

\section{Río Abangares}

El último caso conocido en ese periodo seco 2016 fue el del río Abangares. Los vecinos de Abangaritos en Manzanillo de Puntarenas alertaron a la Alianza sobre la pérdida de flujo en los últimos kilómetros por la existencia de presas que lo desviaban en algunos sectores. Este hecho afectaría su producción anual de sandía en la parte baja, para la que hacen uso artesanal de las aguas del río Abangares con mangueras que riegan por goteo.

Por tal razón, el día 28 de abril se realizó una gira a La Irma de Abangares con estas personas, donde se documentó un desvío estimado en el $40 \%$ del 
caudal natural hacia una hacienda ganadera. Al investigarse la condición, el desvío era ilegal.

Pocos días después llegaron las lluvias y la situación se normalizó, pero este río se mantiene sumamente vulnerable, no solo por la notoria degradación ambiental de la cuenca, sino también por concesiones mineras que alteran su cauce drásticamente con la extracción continua de materiales del cauce.

\section{El caso del río Veracruz, Guacimal de Puntarenas}

Sobre este conflicto se hará extensión detallada, pues Guacimal ha sido uno de los centros regionales de organización y su caso como tal ha presentado complejidades mayores en su extenso desarrollo.

\section{Contexto, razones y denuncia}

Guacimal de Puntarenas es un pueblo de unas 500 personas que ha desarrollado una lucha comunal contra el proyecto de riego Guacimal-Sardinal que recibió una concesión de 163,23 litros por segundo de agua del río Veracruz en el 2011, sin haber tenido el consentimiento informado de la comunidad ni haberse sometido a estudios ambientales.

De haberse ejecutado el proyecto, se habrían entubado cerca de 3/4 partes del agua que tiene el Veracruz en época seca, una fuente que ha mostrado una acelerada disminución de su caudal durante los últimos años, al igual que el río Guacimal, del que es tributario.

El Guacimal es la arteria y el símbolo de la comunidad que lleva su nombre, por lo que la gente se niega a perder la riqueza natural que significan los ríos y se apela al principio precautorio, pues se temen daños irreversibles con la extracción en un contexto de cambio climático que afecta en gran manera todos los ríos de la vertiente del Pacífico.

Imagen 15. Primera manifestación en San José, octubre de 2013.

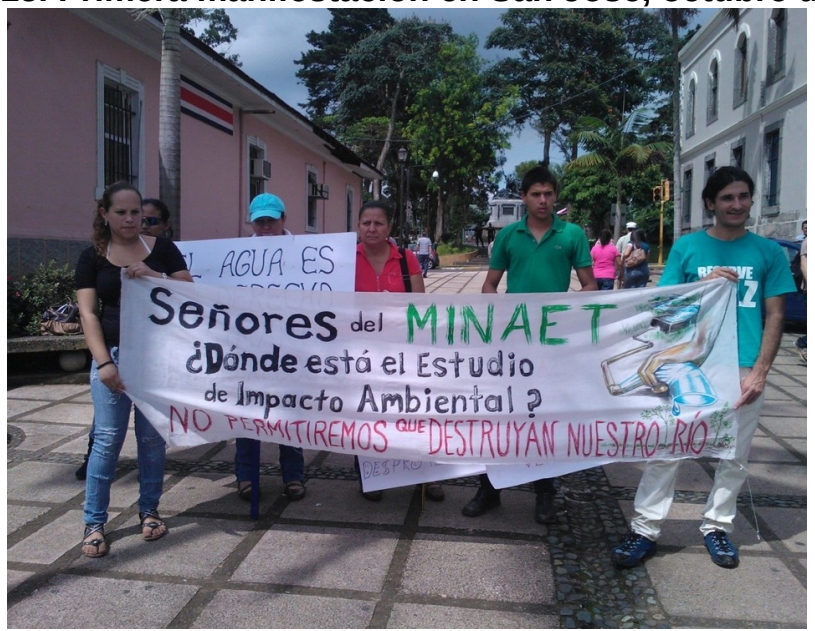

Foto: Dany Villalobos 
14. Expediente 13-015334$007-\mathrm{CO}$ de la Sala Constitucional.
En el año 2013 se elevó el tono al conflicto por el proyecto de riego Guacimal-Sardinal, ya que organizaciones locales del poblado de Guacimal se oponían al entubamiento del río Veracruz para el sistema de riego que beneficiaría sobre todo a grandes finqueros de Coyolar y Sardinal de Puntarenas. En algunos casos ni siquiera habitan en esas comunidades. Calentaba el conflicto porque ese año se sacaba a concurso la licitación para adquirir e instalar las tuberías.

El perfil del caso impuso la necesidad de comenzar por analizar el proceso de aprobación de los permisos ya otorgados por la Dirección de Aguas y la SETENA a través de los expedientes administrativos. Además, se articuló con organizaciones de experiencia en temas ambientales como la Federación Ecologista de Costa Rica (FECON) y abogados especializados en la materia.

\section{Cuadro 1. Actores en el conflicto del río Veracruz, Guacimal}

\begin{tabular}{|l|l|}
\hline \multicolumn{1}{|c|}{ Actor } & \multicolumn{1}{|c|}{ Posición } \\
\hline $\begin{array}{l}\text { Sociedad de Usuarios de } \\
\text { Gua de Los Ángeles de } \\
\text { Guacimal (SUALA) }\end{array}$ & $\begin{array}{l}\text { Beneficiarios del proyecto de riego Guacimal- } \\
\text { Sardinal. Reivindicaban permisos obtenidos: } \\
\text { concesión y viabilidades ambientales. }\end{array}$ \\
\hline $\begin{array}{l}\text { Servicio Nacional de Aguas } \\
\text { Subterránea, Riego y y } \\
\text { Avenamiento (SENARA) }\end{array}$ & $\begin{array}{l}\text { Apoyo económico, técnico y logístico a la } \\
\text { aprobación de permisos, compra de materiales, } \\
\text { licitación y construcción del proyecto de riego. }\end{array}$ \\
\hline $\begin{array}{l}\text { Ministerio de Agricultura y y } \\
\text { Ganadería (MAG) }\end{array}$ & $\begin{array}{l}\text { Apoyo a la justificación de necesidades de los } \\
\text { productores ganaderos. }\end{array}$ \\
\hline $\begin{array}{l}\text { Banco Centroamericano de } \\
\text { Integración económica (BCIE) }\end{array}$ & $\begin{array}{l}\text { Prestamista del Programa de Gestión Integrada } \\
\text { del Recurso Hídrico (PROGIRH) de SENARA. }\end{array}$ \\
\hline $\begin{array}{l}\text { Dirección de Aguas del MINAE } \\
\text { Aprobó la concesión de 163,23 litros por segundo } \\
\text { del río Veracruz }\end{array}$ \\
\hline $\begin{array}{l}\text { Secretaría Técnica Nacional } \\
\text { Ambiental (SETENA) }\end{array}$ & $\begin{array}{l}\text { Aprobó las viabilidades ambientales al proyecto } \\
\text { de riego en 2010 y 2012. }\end{array}$ \\
\hline $\begin{array}{l}\text { Asociación de Desarrollo } \\
\text { Integral y Comité Ambiental de } \\
\text { Guacimal }\end{array}$ & $\begin{array}{l}\text { Representación de la oposición comunal al } \\
\text { proyecto. Análisis y gestión de denuncias. }\end{array}$ \\
\hline $\begin{array}{l}\text { Asociación Administradora de } \\
\text { Acueducto de Guacimal } \\
\text { (ASADA) }\end{array}$ & $\begin{array}{l}\text { De neutral a participación directa en la defensa } \\
\text { del agua por cambio de administración en 2013. }\end{array}$ \\
\hline
\end{tabular}

Fuente: Elaboración propia

Destacables vacíos en materia de impacto ambiental fueron identificados en las viabilidades ambientales obtenidas por la SUALA en 2010 y 2012, lo que legitimaba la oposición comunal al proyecto de riego. Esta situación fue discutida y llevada al público en Asambleas comunales de la Asociación de Desarrollo Integral, donde se informó al pueblo de la ausencia de estudios que fundamentaran ambientalmente al proyecto. Finalmente, en diciembre del 2013, se plasmó el conjunto de demandas en un recurso de amparo ante la Sala Constitucional. ${ }^{14}$ 
El 13 de junio de 2014 se resolvió el recuso y se declaró parcialmente con lugar por amenazar el ambiente sano de la comunidad al pretender explotar hasta un $60 \%$ del agua del río Veracruz sin estudios ambientales, lo que fue considerado irregular por la Sala IV. Se desestimó en la misma la denuncia el incumplimiento del derecho a la información adecuada y veraz, que fue uno de los señalamientos hechos por la comunidad contra la SUALA por haber presentado el proyecto en otros términos en las reuniones iniciales, haciendo sentir engañada e indignada a la población. ${ }^{15}$

\section{Efectos de la primera Resolución Constitucional}

Tras la resolución favorable de la Sala se anuló la viabilidad ambiental otorgada al proyecto de la SUALA ${ }^{16}$ y también la concesión de $163.23 \mathrm{~L} / \mathrm{s}$, dejando vigente otra de $74.72 \mathrm{~L} / \mathrm{s}$ que fue la recomendación técnica dada por el Departamento de Análisis Técnico de la Dirección de Aguas. ${ }^{17}$

Con la resolución se ordenó a la SETENA reconducir los procedimientos de evaluación ambiental y se debieron tomar en cuenta las consideraciones de la Sala respecto a la necesidad de un Estudio de Impacto Ambiental, al no ser un proyecto de bajo impacto ambiental y declararse abiertamente grosero contra el ambiente.

Por efecto del análisis de su Departamento Jurídico, SETENA acogió las observaciones de la Sala, ordenando a la SUALA hacer el Estudio de Impacto Ambiental. ${ }^{18}$ Ante la disconformidad de los desarrolladores, estos solicitaron archivar su expediente 8255-2012, lo que les fue concedido. Con ello pretendieron dar por cerrado el caso y desligarse de la orden de la Sala IV y SETENA, para después abrir un nuevo expediente, del mismo proyecto, pero titulado ahora "Proyecto de Riego SUDAGUA", pretendiendo captar los $74.72 \mathrm{~L} / \mathrm{s}$ de la concesión vigente, otra vez, sin someterse a estudios sobre el impacto ambiental en el río y la comunidad. ${ }^{19}$

A partir de ahí, usando los canales existentes para interponer denuncias en el proceso, la Asociación de Desarrollo, ASADA, y cientos de personas se apersonaron al nuevo expediente, expresando su absoluto rechazo al interés de desvincularse del Estudio de Impacto Ambiental que la Sala IV había considerado fundamental de aplicar para garantizar que no se violara el derecho al ambiente sano de la comunidad.

Todo lo anterior provocó confrontaciones a lo interno del expediente de SETENA, el cual no pudo avanzar ni ser aprobado por presentársele tan complejos cuestionamientos, por lo que la SUALA decidió moverse en el ámbito político y con el favor del MAG logró incluir el proyecto en un Plan General de la Emergencia por Sequía aprobado en marzo del 2015 que se había derivado del Decreto de Emergencia N. ${ }^{\circ}$ 38642-MP-MAG.

La SUALA solicitó el archivo del expediente 13384, señalando que por la inclusión del proyecto en el Plan de Emergencia no requerían la obtención de una viabilidad ambiental. SETENA archivó el proyecto mediante resolución
15. Resolución 2014008486 de la Sala Constitucional.

16. Resolución 2661-2012 SETENA en el expediente 8255-2012 SETENA.

17. Resolución 0993-2010AGUAS-MINAE en el expediente 13753-A

18. Resolución 1360-2014SETENA

19. Expediente 13384-2014SETENA 
1710-2015-SETENA y de inmediato el SENARA dio la orden de iniciar construcciones a finales de septiembre del 2015.

Enteradas las personas locales de que la SUALA y el SENARA buscaban iniciar construcciones sin viabilidad ambiental, se intensificaron las reuniones comunales y se decidió iniciar un proceso intenso de lucha en las calles. La primera acción fue el 18 de octubre con la "Caminata por el río Veracruz". Fue en esta actividad que la comunidad empezó a ejercitar el uso de la vía pública en el propio poblado de Guacimal para hacer ver ante los desarrolladores e involucrados en el proyecto que no iban a dejar pasar tuberías.

Imagen 16. Tuberías de 12 pulgadas instaladas.

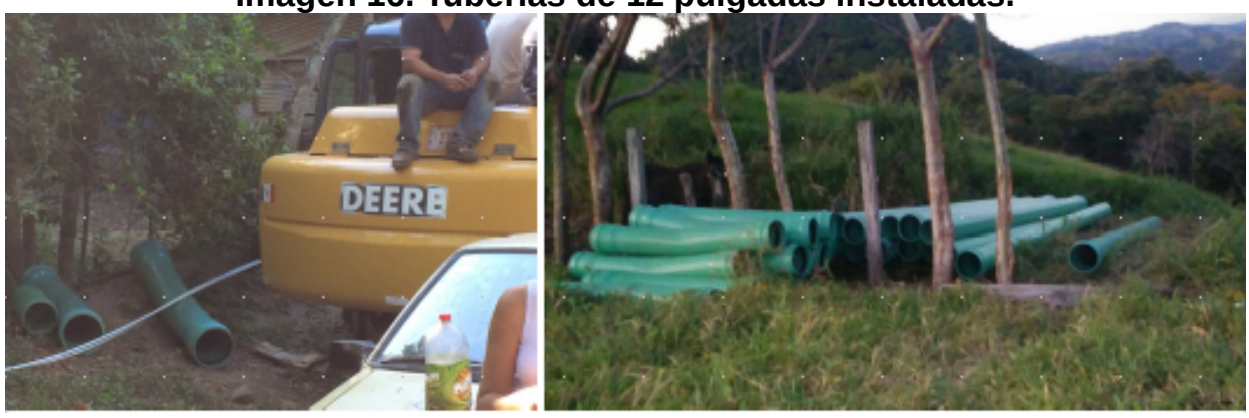

Fotos: Verónica Sheehan y Dany Villalobos

Imagen 17. "Caminata por el río Veracruz" en Guacimal. Octubre de 2015.
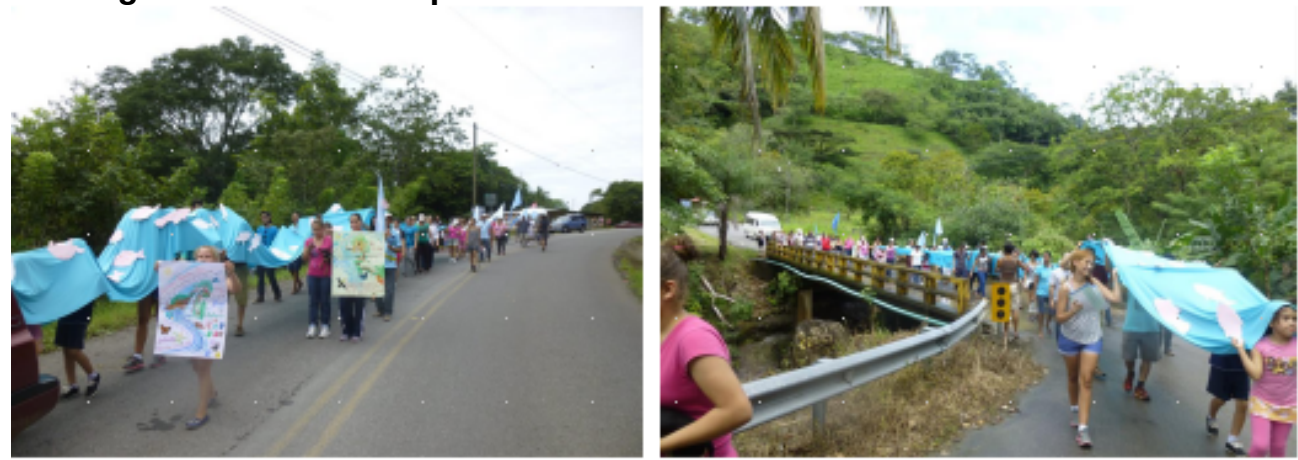

Fotos: Dany Villalobos

Las construcciones habían iniciado en Sardinal de Puntarenas, dentro de las haciendas que eran destino final del agua, dejando para último el tramo de llegada al río Veracruz en donde se ubica el pueblo Guacimal. El avance era tenso y la Asociación de Desarrollo local interpuso inmediatamente una "gestión de desobediencia" en Sala IV. Además, se gestionó un nuevo recurso de amparo firmado por unas cien personas de la comunidad, quienes pedían reconocer la violación al derecho ambiental con la inclusión del proyecto en el 
Plan de la Emergencia que le había exonerado de obtener viabilidad ambiental.

\section{Reclamo a la Municipalidad de Puntarenas}

Como los procesos judiciales eran inciertos, mientras la construcción avanzaba, el pueblo decidió en asamblea realizar un bloqueo en la carretera interamericana para llamar a cuentas tanto a la Municipalidad como al Ministerio de Ambiente por las construcciones realizadas sin permiso de construcción municipal ni viabilidad ambiental de SETENA.

Dicho bloqueo se realizó en la mañana del 14 de diciembre de 2015 en Sardinal (Villalobos 2015). Se hizo la toma de un solo carril y de inmediato se presentaron los oficiales de la zona a intermediar en el conflicto. En él participaron personas de Guacimal, Santa Rosa y Aranjuecito, desde niños con sus padres hasta adultos mayores.

Imagen 18. Bloqueo en la carretera interamericana, diciembre de 2015.

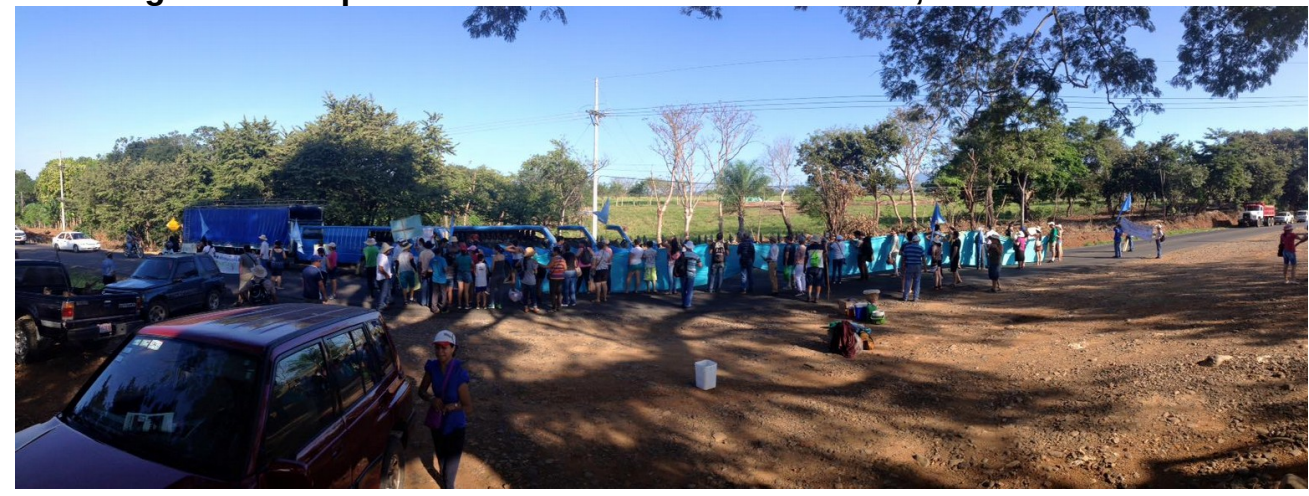

Foto: David Villalobos.

Aún así, la orden superior en determinado momento de la negociación fue que se levantara voluntariamente el bloqueo o se procedería a aprehender a las personas, lo que causó malestar en los manifestantes que decidieron quedarse hasta que se hiciera presente el alcalde, Rafael Rodríguez, al que se señalaba de favorecer el proyecto por sus vínculos políticos con el regidor distrital y muchos de los beneficiarios del riego.

Sin embargo, ante la llegada de antimotines preparados para dispersar con gases lacrimógenos, la concentración decidió por seguridad tomar rumbo hacia la Municipalidad para reunirse allí con el alcalde y el presidente del Concejo Municipal para exigir la intervención municipal ordenando la detención de las obras.

El proyecto no contaba con permiso de construcción, lo que ratificó el jefe del Departamento Municipal de Construcciones, Arturo Morera. Por ello, se exigió un espacio en la sesión municipal de ese día, en la que se presentó una 
20. Como base jurídica se usó el documento aprobado por el Concejo Municipal de Upala en que se declaró moratoria a proyectos hidroeléctricos, contextualizando la situación de las concesiones para riego.

21. Expediente 16-0011431027-CA del Tribunal Contencioso Administrativo. propuesta de moratoria jurídicamente fundada ${ }^{20}$ a los proyectos de riego en la zona, hasta que no cumplieran con los Estudios de Impacto Ambiental de los que carecían. Esto supondría la detención inmediata de las obras en construcción. Pero, la propuesta fue reprobada por el Concejo Municipal, porque algunos regidores alegaron riesgo jurídico si aprobaban una moratoria a proyectos que ya contaban con permisos de operación.

Ante esta definición, se procedió a interponer un recurso extraordinario de revisión contra un acuerdo municipal que había dado "voto de apoyo" al proyecto en 2011. Con ese criterio político del Concejo Municipal, el SENARA y desarrolladores afirmaban haber cumplido con el permiso municipal para construir. Esto no tenía cabida lógica para los líderes comunitarios, por lo que, al no revocarse dicho Acuerdo Municipal, se abrió un proceso judicial contra la Municipalidad de Puntarenas a inicios del 2016, el cual aún está en proceso. ${ }^{21}$

\section{Acción directa para detener el proyecto}

Con los recursos de amparo en espera de resolver y sin que se dieran las medidas cautelares solicitadas por la comunidad, el 7 de enero del 2016 se procedió a tomar simbólicamente la maquinaria, que tras la jornada laboral y una falla mecánica había quedado en vía pública, en el cruce de Santa Rosa. A las 4:30 a.m. llegaron las primeras personas al lugar, completándose durante la mañana la toma con decenas de personas que impedían cualquier movimiento hasta que no hubiera intervención de las autoridades y un órgano oficial declarara la detención de las construcciones. Y así sería finalmente.

\section{Imagen 19. Detención comunal de las construcciones el 7 de enero de 2016 en} el cruce de San Rosa

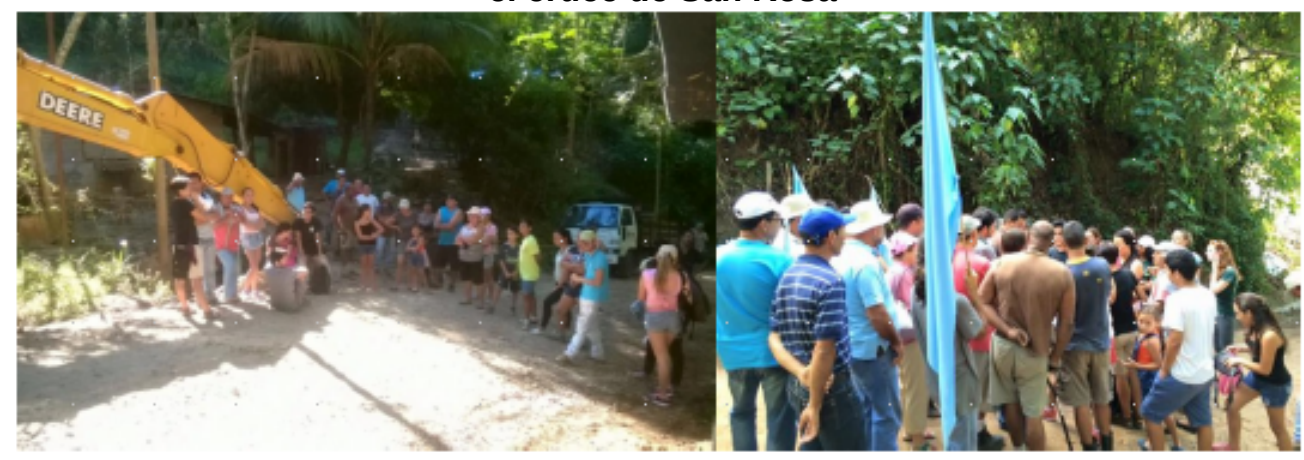

Fotos: Grupo Ríos Libres

Se le expusieron los motivos de la acción colectiva, con papeles en mano, a la Fuerza Pública, a un miembro de la Dirección de Inteligencia y Seguridad (DIS) y vía telefónica a Raymi Padilla del departamento de Asuntos Políticos y Diálogo Ciudadano del Viceministerio de la Presidencia, que abogó para que Patricia Quirós, la Gerenta General de SENARA, emitiera un correo ofi- 
cial aceptando una tregua de 15 días a las construcciones, lo que serviría para iniciar un proceso de diálogo en búsqueda de resolver en conflicto mediado por la Viceministerio de la Presidencia. Este dialogo iniciaría el día 18 de enero en Casa Presidencial, Zapote.

El día de la reunión se organizó una manifestación sin precedentes en San José. Casi 100 personas de Guacimal acompañaron a los representantes comunales a Casa Presidencial, con mantas y pancartas que expresaban sus mensajes en defensa de los ríos Veracruz, Aranjuecito y Acapulco. En la mesa, el logro principal fue extender 15 días más la paralización de las obras, por lo que se completaría un mes sin avances en el proyecto, lo que daría un aire a la comunidad en espera de una posible resolución de los recursos interpuestos. SENARA sostuvo que solo una resolución judicial los detendría. ${ }^{22}$

Imagen 20. Movilización a Casa Presidencial el 18 de enero de 2016.

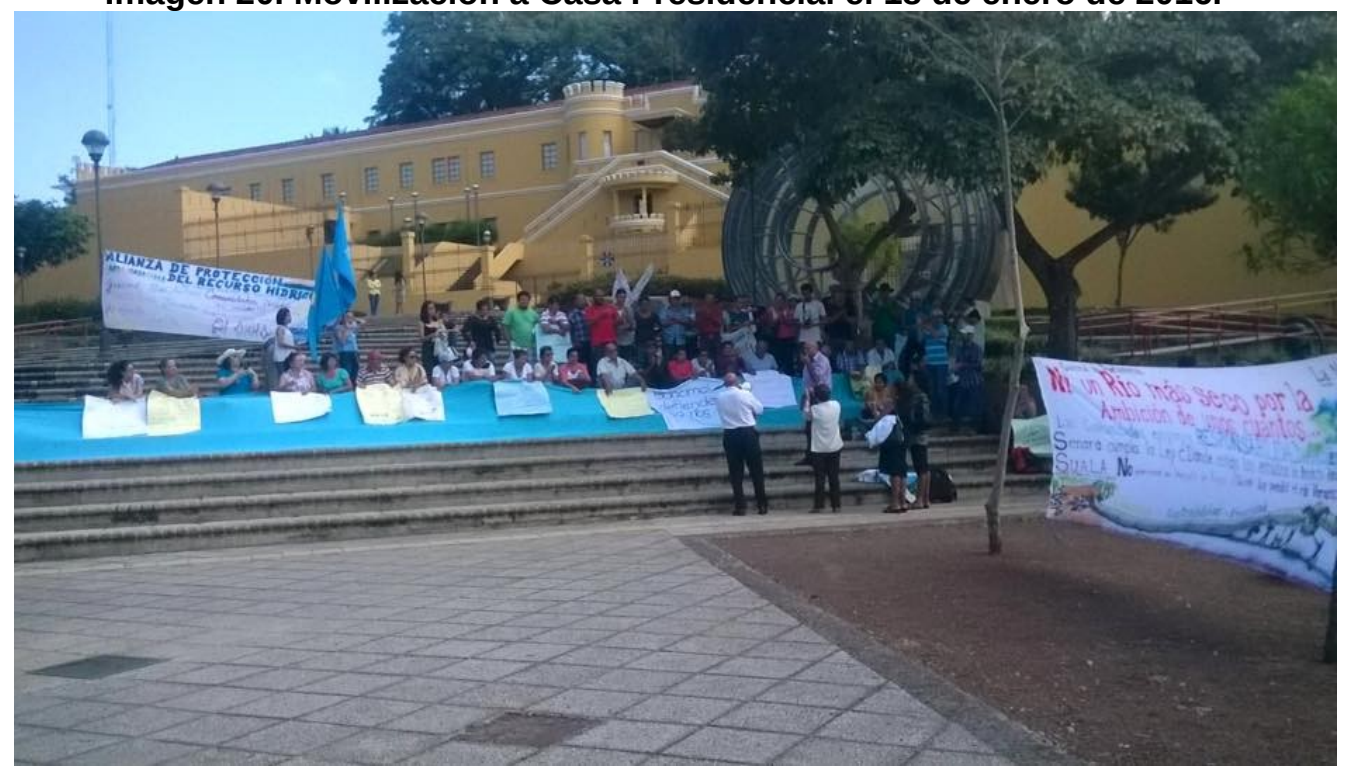

Foto: Dany Villalobos.

SENARA alegó que el proyecto era necesario para generar empleos y traer desarrollo a la zona, situación que rebatió directamente Elpidio Ramírez, de Santa Rosa, quien cuestionó si tenían información sobre los empleos generados por el proyecto que secó el río Acapulco, porque no se conocía uno solo. El representante de SENARA reconoció que no se tenía esa información sobre empleos generados. La insostenibilidad del argumento del "desarrollo" quedó evidenciada y la indignación de los representantes comunales se mantenía al no reconocerse las irregularidades del proyecto en construcción.
22. En la "Minuta de reunión en el Despacho del Ministerio de la Presidencia, San José, 18 de enero de 2016." 
23. Resolución 2016002065. Expediente 15-015225-0007CO.

\section{Continuidad de las construcciones}

Llegando el fin del periodo de parálisis, SENARA emitió la orden de reiniciar obras el lunes 8 de febrero. El día anterior por la tarde se reunió también la comunidad para discutir las acciones que iban a proceder. Se acordó mantener coordinación y disposición. Se nombró un comité de vigilancia que se encargaría de informar los movimientos de la construcción, cuya ruta de reanudación se desconocía. En el momento en que regresaran a vía pública, el pueblo les volvería a impedir cualquier trabajo interponiéndose en el sitio, tal como se hizo el 7 de enero en el cruce de Santa Rosa.

Durante los siguientes 10 días salieron siempre algunas personas que se relevaban para realizar la vigilancia y otras más apoyaban preparando comidas colectivas en la vía pública o llevando meriendas. Fernando Sánchez y Jorge González fueron dos personas de la comunidad que estuvieron cada día en rol de vigilancia desde la primera hora.

Las excavaciones e instalación de tuberías venían haciéndose por los cerros de Los Ángeles, en una finca privada. Por lo quebrado del terreno, ese tramo les tomó varios días, pero ya estaban a punto de llegar al cruce de Santa Rosa nuevamente, donde la comunidad tenía su puesto de control por ser una zona de paso forzado en algún momento de la construcción. Se preveía que ahí se repetiría la acción directa.

Tras algunos intercambios de palabras al acercarse la excavación al sitio donde se congregaban los grupos comunitarios, la tensión había aumentado y muchos pensaban que iban a ser inevitables los altercados en poco tiempo. Unos 200 metros separaban a los peones del sitio donde se produciría el encuentro.

No obstante, sucedió lo esperado por los líderes comunales en el momento justo: el 18 de febrero empezaron a retirarse las maquinarias y los peones. La noticia aún no estaba clara, pero la Sala Constitucional había resuelto a favor uno de los recursos de amparo interpuestos por el pueblo, ordenando excluir al proyecto de riego Guacimal-Sardinal del Plan de Emergencia y detener inmediatamente las obras. ${ }^{23}$

Entre quienes no terminaban de creer la noticia, las llamadas confirmativas de quienes asesoraban en el tema legal hicieron que la gente se sintiera segura y organizaron una caravana de vehículos que se cargaron de gente que celebraba la resolución favorable al pueblo y mantenía así la paz en el proceso de defensa del río Veracruz. Las actitudes impositivas con que se venía avanzando en las construcciones, sin permisos legales, habían puesto en la mente de las personas los peores escenarios, por lo que la tensión liberada con esta resolución fue mucha.

\section{Reactivación del conflicto en SETENA}

El proyecto estaba archivado en SETENA, pero en septiembre de 2016, con la resolución 1639-2016-SETENA, se retomó la evaluación, lo que es inmediatamente interpelado por la comunidad, al oponerse a la reanudación de un 
expediente que había sido archivado por petición de los mismos desarrolladores. Además, se le volvía a bajar la categoría al impacto del proyecto para incumplir con estudios y, sobre todo, anular las manifestaciones de oposición comunal.

Esto llevó a la comunidad a organizar una nueva manifestación en SETENA con apoyo de comunidades que participan de la Alianza y organizaciones ambientalistas de San José. Participaron unas 75 personas y ahí mismo se presentaron recursos administrativos contra la reactivación del expediente 13384-2014.

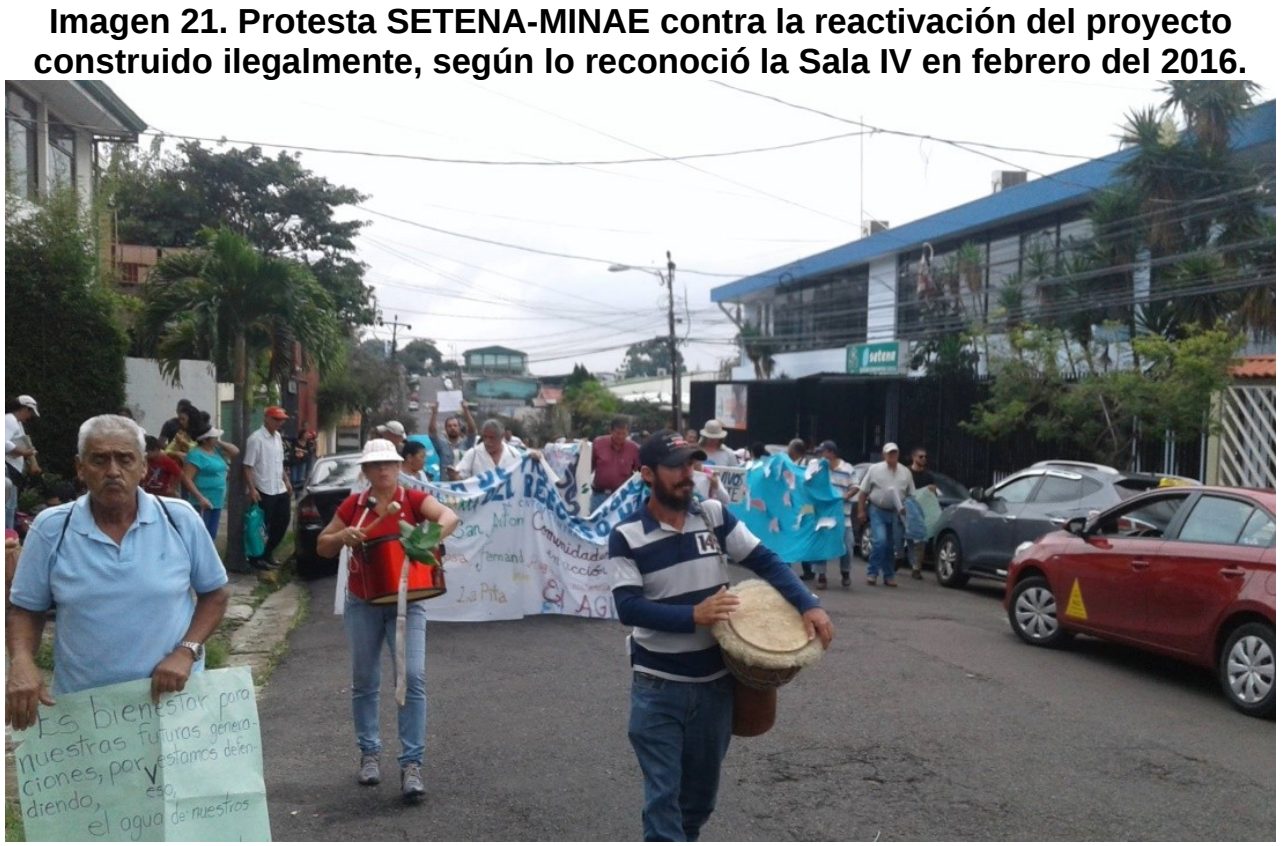

Foto: Dany Villalobos.

Con un recurso de revocatoria se confronta actualmente este nuevo intento de avanzar con la obtención de una viabilidad ambiental en SETENA para un proyecto parchado de irregularidades. Al momento de su paralización, avanzó cerca de un $70 \%$ en la instalación de las tuberías según el SENARA. Hoy, la inversión hecha es el principal medio de presión de los desarrolladores para insistir en la captación del agua del río Veracruz.

\section{Caducidad de la concesión}

Desde octubre del 2015 se había denunciado ante la Dirección de Aguas que ya la concesión debía declararse caducada por haber transcurrido para entonces casi cinco años sin usarse. Con base en el artículo 26 de la Ley de 
24. Resolución R-209-2017MINAE. A pesar de que la SUALA apeló, el MINAE rechazó la apelación y dejó en firme la declaración de caducidad.
Aguas, tener una concesión por tres años sin uso es causa de caducidad y, por eso, se presentó la solicitud, como consta en el expediente 13753-A.

Esta denuncia derivó en la creación de un Órgano Director dentro del MINAE para resolver. Para febrero del 2017, dicha instancia convocó a la primera audiencia de este proceso donde se verificaría el hecho denunciado; es decir, si el desuso de la concesión era real. En esta audiencia que finalmente se realizó en marzo, se dejó por sentada la realidad de que la explotación nunca se había dado tras pasar ya más de seis años desde que se otorgó la concesión.

Habiendo pasado las audiencias, el Órgano Director hizo su balance y recomendación al Ministro de Ambiente para resolver el caso y emitir la resolución final. A pesar de la oposición de la SUALA a que se le anulara la concesión, el 7 de junio el MINAE declaró caducidad definitiva y extinción del derecho, dándole un cierre al conflicto contra esta concesión para riego. ${ }^{24}$

\section{Propuesta: Veracruz para el agua del futuro}

El valor de tener un río como el Veracruz libre, según las reflexiones generales de la comunidad, es que se asegura una fuente potencial de agua potable para un futuro incierto en el tema de fuentes de agua de la zona. La calidad del agua del Veracruz es cualitativamente destacable, pues en su microcuenca recorre un territorio libre de urbanización y la intervención humana ha sido básicamente por la implantación de pastizales para ganadería extensiva.

Ante esta motivación de proteger un río de aguas limpias, el sábado 8 de octubre del 2015 había sido presentada en Sardinal de Puntarenas, ante el AyA, una propuesta para la gestión comunitaria de las cuencas. Estuvo presente la presidenta ejecutiva, Yamileth Astorga, quien acogió de manera positiva el planteamiento y se comprometió a apoyar para que, en un mediano o largo plazo, se pueda invertir en estas iniciativas integrales para consumo humano (Villalobos, 2015). No obstante, el desarrollo del conflicto con las concesiones a sociedades privadas ha mantenido en pausa el trabajo en esta propuesta.

Los resultados de varias entrevistas realizadas durante el 2016 por el autor y estudiantes de la Universidad de Costa Rica, en comunidades de la zona baja de Puntarenas como Malinche y Orocú de Chomes, revelan la existencia de problemas con hierro y manganeso en los acueductos que se abastecen mediante pozos.

El consumo sostenido de agua de mala calidad preocupa a la gente y una fuente de mayor calidad que abastezca a varias comunidades sería una buena alternativa de inversión para corregir el problema en comunidades que presentan esta vulnerabilidad. Sumado a esta situación, existen riesgos de contaminación por agroquímicos y otros agentes en la parte baja. Además, hay pozos que han tendido a la merma como se ha ejemplificado en algunos de los casos expuestos atrás. 
Imagen 22. Memoria de reunión con AyA en Sardinal de Puntarenas, donde se propuso el plan de manejo de cuenca del río Veracruz y otros.

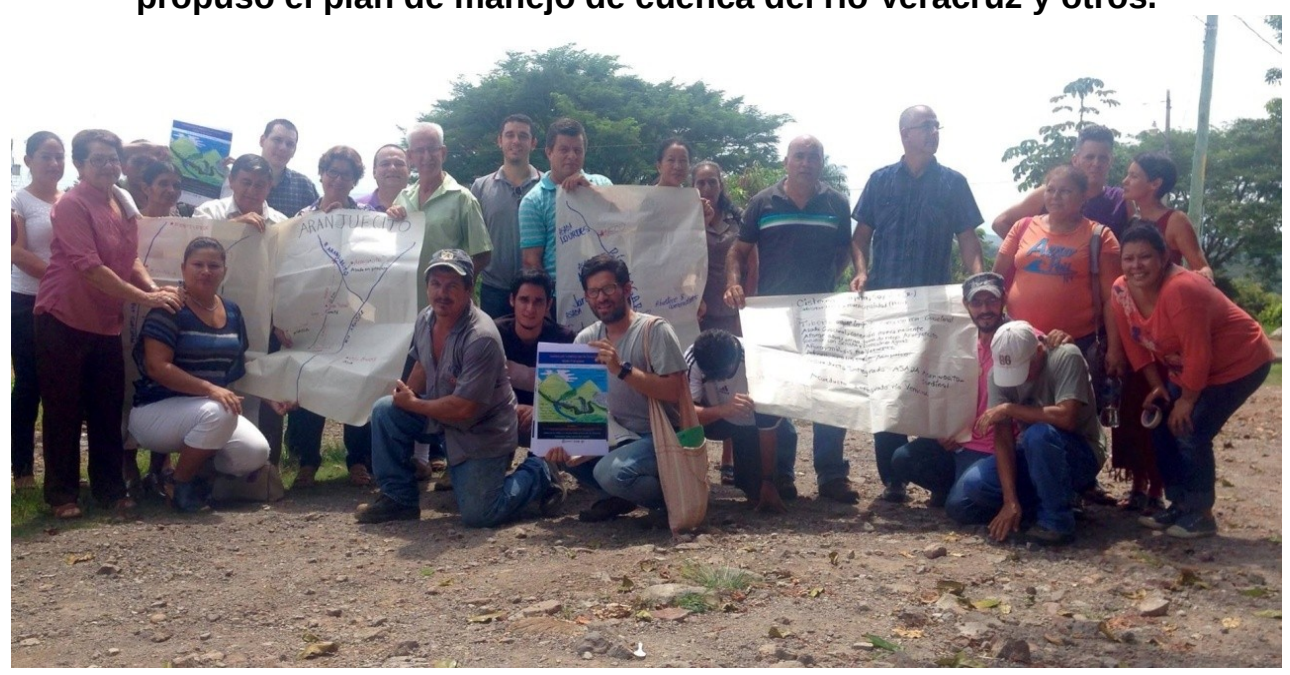

Foto: Kioscos Socio-Ambientales UCR

La idea de disponer el río Veracruz, como esa fuente que solventará las necesidades a mediano o largo plazo, sigue estando planteada y es sostenida y aceptada por la comunidad de Guacimal. Resuelto ya el destino final de la concesión para riego en dicho río, se espera emprender un proceso que permita a muchas comunidades beneficiarse del agua tal y como se establece por ley: prioritariamente para consumo humano.

\section{Panorama general de la problemática hídrica}

\section{¿Cómo se perciben los problemas hídricos a nivel local?}

Durante el proceso de entrevistas, reuniones y actividades relacionadas con el agua, se puede establecer un desglose de preocupaciones generales asociadas con la condición de las fuentes de agua, como se observa en el cuadro 2.

Se puede entender cómo los pobladores se preocupan sobre todo cuando perciben la disminución del agua, que es asociada con la falta de áreas de protección y deforestación histórica. También, por la condición química del agua, que se relaciona con la exposición a fuentes de contaminación como aguas servidas o las piñeras, igual que las altas concentraciones de hierro y manganeso que afectan algunos acueductos que se abastecen mediante pozos. 
Cuadro 2. Principales preocupaciones respecto a las fuentes de agua según personas locales.

\begin{tabular}{|l|l|}
\hline Categoría & Razonamiento \\
\hline 1) la condición física del agua & $\begin{array}{l}\text { Escasez. Reducción de las áreas de } \\
\text { protección }\end{array}$ \\
\hline 2) la condición química del agua & Contaminada o expuesta a contaminación \\
\hline 3) la condición ecológica del agua & Afectación a la biodiversidad en los ríos \\
\hline 4) la condición jurídica del agua & En dominio público o concesión a privados \\
\hline 5) la condición social del agua & $\begin{array}{l}\text { Distribución, formas de uso y beneficios } \\
\text { derivados }\end{array}$ \\
\hline
\end{tabular}

La situación ecológica vincula los cuerpos de agua con las necesidades de otros seres vivos, especialmente peces, camarones y nutrias que se pueden ver afectadas por las captaciones. La situación legal, que implica saber si los usos cuentan o no con permisos y, si están afectando, por qué se dieron. Finalmente, en la parte social, se cuestiona principalmente la distribución, las prioridades actuales en el acceso, la concentración de los beneficios por el acaparamiento y la incongruencia del discurso del desarrollo que se usa para justificar la entrega de agua a ciertos sectores económicos.

Estas reflexiones han implicado una aceptación general del cambio climático como una realidad en la zona, incluso por parte de las personas que prefieren mantenerse distanciadas de los conflictos locales por agua. Además, se acentúan los cuestionamientos hacia las instituciones responsables en materia ambiental como el MINAE, la SETENA, la Dirección de Aguas, el SENARA y en menor medida al MAG y los propios tribunales de justicia cuando no dan la respuesta esperada en los casos.

Las personas de estas comunidades de Puntarenas han hecho notables esfuerzos para poder movilizarse a exponer las problemáticas de la zona a las dependencias del MINAE en San José y a la Municipalidad de Puntarenas. Actividades que van desde las rifas, las cocinadas comunales y las donaciones de vecinos para financiarse han sido la muestra de la autodeterminación que tiene la gente para seguir luchando. El acercamiento con las instituciones ha dejado grandes críticas al trabajo de estos órganos estatales. Se nota su inclinación hacia la privatización del agua y su incapacidad de atender adecuadamente los planteamientos de las comunidades en este sensible tema.

\section{Ineficiencia estatal en la administración sostenible del agua}

25. Información extraída de los documentos "Reporte técnico aforos (todos)" y "Concesiones por nombre de la fuente" para la Unidad Abangares. Registro Nacional de Concesiones, MINAE. Obtenido en línea el $11 / 05 / 2016$
Además de confrontar los desvíos ilegales de caudales observados en varios sitios, para el año 2016, ante los múltiples reportes de ríos secos en la parte baja, la Alianza realizó una investigación sobre las concesiones otorgadas por la Dirección de Aguas en los ríos de Puntarenas. ${ }^{25}$

En dicho análisis se comprobó cómo la ausencia de controles por parte de la Dirección de Aguas había permitido explotaciones que superaban el propio 
caudal aforado en años anteriores en tres ríos de Puntarenas, lo que originando los colapsos ambientales observados por la población local.

Imagen 23. Concesiones comparadas con los caudales registrados por la $\mathrm{Di}$ rección de Aguas en 3 ríos afectados durante la estación seca.

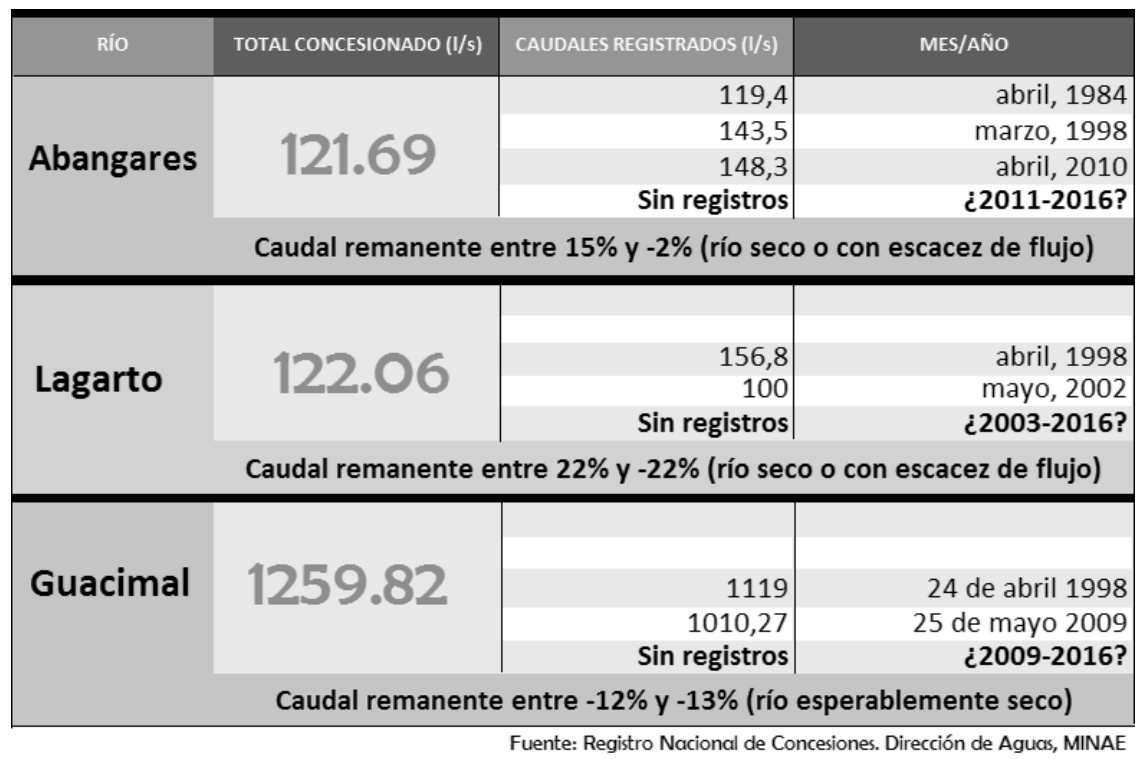

Esta información se difundió por redes sociales y medios de comunicación con el fin de hacer saber a la población que la Dirección de Aguas estaba siendo corresponsable en los desastres ecológicos que se derivaran de la destrucción de los ríos por actividades agroindustriales en la zona baja.

Como se observa, el río Abangares puede llegar a tener menos de $120 \mathrm{~L} / \mathrm{s}$ y tiene concesiones por más de ese volumen; el Lagarto también tiene más de $120 \mathrm{~L} / \mathrm{s}$ concesionados y su caudal ha llegado a registrar incluso solo 100 L/s; y el río Guacimal tenía 1259 L/s concesionados en una fuente que ha llegado a tener solo $1010 \mathrm{~L} / \mathrm{s}$.

Se puso al descubierto la contradicción de haber permitido concesiones que, sumadas, superaban los registros históricos de agua en cada río. Además de eso, se lanzaba la crítica al descontrol, evidente en una base de datos con registros aleatorios que están lejos de poder siquiera aproximarse científicamente la realidad hídrica de los ríos. Todo ello es contrario a lo que dictan los principios de la Ley General de Administración Pública en su artículo 16, sobre la razón y la ciencia como base para sustentar los actos administrativos; en este caso, permisos de explotación de un bien de dominio público como el agua. 
26. Argumento expresado por diferentes funcionarios de la Dirección de Aguas reuniones sostenidas durante el conflicto de Guacimal.

\section{Conclusiones}

Ante la panorámica que ha sido reconstruida mediante la participación en los movimientos sociales que han defendido el agua en el cantón Central de Puntarenas, los desafíos en el tema hídrico de la zona se muestran complejos y se proyectan a tener continuidad, tanto por el contexto climático como por el modelo de desarrollo capitalista que permanece inalterable desde el siglo XX en Puntarenas y es defendido por las propias instituciones del Estado en el siglo XXI, a pesar de las discusiones internacionales en materia de protección y sostenibilidad ambiental.

Personas locales han cuestionado el modelo de concesiones, planteando públicamente su desacuerdo con la forma en que se maneja o se pretende manejar el recurso hídrico por parte de actores públicos y privados. Los conflictos han sido tanto por reacción como por principio preventivo. Las experiencias han permitido acercamiento entre personas de diversas comunidades que se concientizan y actúan valiéndose de su derecho a un medio ambiente sano y ecológicamente equilibrado, al tiempo que reivindican valores como la colectividad y la defensa del interés público.

En el caso de los ríos, la legislación sobre el agua mantiene vacíos claros en el tema de caudales remanentes, pues aunque la Ley de Aguas expresa que no se deben dejar secas las fuentes al permitirse los aprovechamientos, la Dirección de Aguas permite explotar hasta el 90\% del agua de un río en época seca y dejar un teórico $10 \%$ de agua como supuesta garantía ambiental. Ello potencia las sequías totales de ríos y, en general, somete a las poblaciones de especies acuáticas a un alto estrés hídrico.

La carencia de información hidrológica para entregar concesiones de tan alta dimensión ha sido reclamada por representantes de las comunidades tras revisar los registros oficiales de información hidrológica. La respuesta que ha dado la Dirección de Aguas es que su oficina debe trabajar con lo que haya, porque no puede entrabar el desarrollo normal de las actividades productivas en el país. ${ }^{26}$

Por su parte, los funcionarios del SENARA han defendido en los espacios de diálogo su modelo de explotación de grandes cantidades de agua, justificando que, si no se dan estos proyectos, igualmente los ríos serán desviados por las grandes empresas antes de llegar al mar. Es conocido entonces por estas autoridades el problema de la alteración de los caudales en la parte baja denunciada por personas de comunidades, pero en lugar de tratar de corregirlo como responsables legales en el campo de manejo de cuencas, usan el problema para justificar sus nuevos proyectos de riego en la cuenca media-alta.

Varias otras iniciativas de apoyo del SENARA a nuevas Sociedades de Usuarios de Agua son ya conocidas en la zona, lo que podría desencadenar nuevas confrontaciones cuando amenacen otros ríos y quebradas valorados por las poblaciones. 
La dirección regional de AyA ha sido criticada en dos de los conflictos por falta de respuesta a las crisis en los acueductos comunales. La tramitología es a veces la justificación para no ofrecer soluciones y eso lleva a la gente a indignarse, pues el Estado se percibe inoperante en su responsabilidad de servir al interés público y cumplir las demandas sociales prioritarias como el agua para consumo humano, en un contexto donde otras instituciones son complacientes con las grandes empresas que reciben permisos para explotar a placer las fuentes de agua.

Los conflictos expuestos no han llegado a una conclusión. Las comunidades siguen manteniendo procesos legales y administrativos abiertos contra proyectos como el de Santa Rosa, Aranjuecito y Guacimal. También, quienes aún no han entrado en procesos de este tipo están atentos en los "veranos"27 a los desvíos de ríos por parte de finqueros, principalmente en la zona baja, para proceder a destruir inmediatamente las presas cuando su condición jurídica lo permita.

Un desafío abismal en contra de las organizaciones locales son los permisos que se siguen otorgando en la SETENA, la Dirección de Aguas y la Dirección de Geología y Minas, pues estos plantean una confrontación entre la tecnocracia y las comunidades, con desigualdad de condiciones. Las grandes empresas son beneficiarias de la gestión estatal al legalizar las explotaciones de aguas y cauces de ríos en perjuicio de comunidades que, además de ser lejanas a las oficinas centrales donde se toman las decisiones finales, no siempre cuentan con el grado de preparación, las herramientas o los recursos para involucrarse en procesos legales.

También cabe señalar que en la práctica son un verdadero límite los medios que el Estado dispone oficialmente para supuestamente hacer cumplir el derecho a la información adecuada y veraz de las personas en comunidades sobre proyectos que solicitan bienes de dominio público como el agua. Se consideran oficiales y viables socialmente los proyectos después de ser publicados tres veces en el diario La Gaceta, que no es de manejo popular.

Es socialmente inviable sostener este mecanismo, a no ser que existiera un sistema de notificaciones sistemáticas desde las instituciones centrales hacia las locales, con lo que se asegure que la información sobre proyectos en la zona esté efectivamente llegando a las personas, como portadoras de derecho sobre bienes de dominio público como el agua y el ambiente. Hasta ahora ha sido marginal la posibilidad de una participación efectiva en la toma de decisiones conscientes de las personas locales sobre su territorio.

La Alianza sigue siendo una red que se basa en el trabajo voluntario y financia de forma autónoma los costos en materia legal. Por eso, abrir un proceso de este tipo por cada irregularidad en el tema hídrico se vuelve complicado de asimilar, quizá insostenible, en este panorama de adversidades y desventajas técnico-legales de las comunidades.

Es con el apoyo mutuo entre personas y comités locales, así como de organizaciones no gubernamentales y las mismas universidades públicas, que se buscan fortalecer otras vías como el acceso a la información, la organización
27. Término popular con el que se conoce a la estación seca en Costa Rica. 
comunitaria y la acción social en torno a los problemas de agua en Puntarenas, a la espera de que el tiempo vaya destapando nuevas confrontaciones por efecto de un modelo de explotación de agua abiertamente insostenible, que contradice el discurso oficial del Estado costarricense en materia ambiental.

\section{Bibliografía}

Alianza de Comunidades por la Defensa del Agua. (2016). Secan más ríos: Abangares, Guacimal, Aranjuez, Aranjuecito, Acapulco y Lagarto. Diario Elpaís.cr.

Araya Villalobos, María Cristina. Sanabria Valverde, Nury. 2010. Climatología de periodos quincenales secos, húmedos y de transición en las regiones climáticas del Norte y Pacífico Norte, Costa Rica. Tesis de Licenciatura. Universidad Nacional de Costa Rica.

Bolaños Vargas, Eduardo. (2005, junio 2). Conflicto por aguas en Monteverde. Acusan a 17 vecinos por protesta. Semanario Universidad. Calderon, Javier y López, Diana. 2013. Orlando Fals Borda y la Investigación Acción Participativa: Aportes en el proceso de formación para la transformación. Memoria del I Encuentro hacia una Pedagogía Emancipatoria en Nuestra América realizado en el Centro Cultural de la Cooperación Floreal Gorini , 11 de noviembre.

Cascante Lizano, Sharon. (2015, octubre 5). La Pita de Puntarenas lleva tres meses sin agua. La Prensa Libre.

Cifuentes Jara, Miguel. 2010. ABC del cambio climático en Mesoamérica. Turrialba, Cartago, Costa Rica. 2003.

Dirección de Aguas. (22/11/2010). Resolución 0993-2010-AGUAS-MINAE. Expediente 13753-A. San José, Costa Rica.

Dirección de Aguas. (22/01/2015). Documento DA-0164-2015. Expediente 14-01977- 0007-CO. San José, Costa Rica.

Dirección de Aguas. (22/06/2015). Informe AT-2285-2015. Expediente 12608-

A. San José, Costa Rica. 
Dirección de Aguas. (15/04/2016). Reporte técnico aforos (todos). Unidad Abangares. Registro Nacional de Concesiones, MINAE. Obtenido 11/05/2016

Dirección de Aguas. (15/04/2016). Concesiones por nombre de la fuente. Unidad Abangares. Registro Nacional de Concesiones, MINAE. Obtenido 11/05/2016

Era Verde (2015, diciembre 8). Río Acapulco seco por proyecto de riego en Puntarenas. Canal UCR.

FECON. (2016, mayo 25). Concesionar más agua que la existente está secando los ríos. Diario Elpaís.cr.

Gamboa, Jeymer. (2005, noviembre 17). Monteverde. Conflicto por agua. Semanario Universidad.

Garita, Andrés y Solano, Hugo (2014, marzo 24) Bloquean paso por Miramar en la Interamericana Norte. Periódico La Nación.

Park, Peter. 1990. Qué es investigación-acción participativa. En Investigación-acción participativa. Orígenes y desarollos. Editorial Popular. Madrid, España. 135-174.

Méndez, I. (2016). Acta de observación policial. Ministerio de Seguridad Pública, Delegación Policial Abangares. 29 de marzo del 2016.

Ministerio de Ambiente, Energía y Telecomunicaciones (2008). Plan Nacional de Gestión Integrada de los Recursos Hídricos. San José, Costa Rica.

Sala Constitucional. (13/06/2014). Resolución 2014008486. Expediente 13015334-0007-CO. San José, Costa Rica.

Sala Constitucional. (24/04/2015). Resolución 2015005621. Expediente 1401977- 0007-CO. San José, Costa Rica.

Sala Constitucional. (12/02/2016). Resolución 2016002065. Expediente 15015225-0007-CO. San José, Costa Rica.

Secretaría Técnica Nacional Ambiental. (15/06/2011) Resolución 1383-2011SETENA. Expediente 1087-2010 SETENA.

Secretaría Técnica Nacional Ambiental. (Resolución 2661-2012-SETENA. Expediente 8255-2012 SETENA. 
Secretaría Técnica Nacional Ambiental (05/09/2016). Resolución 1639-2016SETENA. Expediente 13384-2014 SETENA.

Villalobos, Nathalia. (2015, octubre 13). Comunidad de Puntarenas presentó propuesta de manejo comunitario de agua.

Villalobos, Nathalia. (2015, diciembre 11). Vecinos de Guacimal organizan cierre parcial de carretera Interamericana por defensa del río Veracruz. Diario Elpaís.cr. 